\title{
YLLAPA USNO: RITUALES DE LIBACIÓN, CULTO A ANCESTROS Y LA IDEA DEL USHNU EN LOS ANDES SEGÚN LOS DOCUMENTOS COLONIALES DE LOS SIGLOS XVI-XVII
}

\author{
José Luis Pino Matos*
}

\begin{abstract}
Resumen
En los Andes, los rituales de libación fueron la práctica social más importante en las ceremonias Inka, en las que participaban todo el colectivo social empezando por los personajes más importantes como los gobernantes, las deidades y los "Yllapa" o cuerpos de los difuntos considerados como principales. Es en este contexto que el "Ushnu" fue el correspondiente escenario de estos rituales con un protagonismo central, y que este fue percibido y descrito sutilmente en los registros coloniales españoles. El estudio en base a un análisis de las fuentes históricas, muestra la descripción en detalle de estos lugares así como la complejidad y multifuncionalidad del "Ushnu," en relación a los rituales de libación y culto a los ancestros por parte de las sociedades andinas. También se plantea la posibilidad del uso en gran número de los "Yllapa Usno" ó recipientes para libaciones que pudieron tener un carácter mueble, y que cada ancestro de cada grupo social poseía el suyo para poder brindar.
\end{abstract}

Palabras clave

Ushnu, Yllapa Usno, Ancestro, Ritual, Libación, Etnohistoria, Estado Inka.

\begin{abstract}
In the Andes, the rituals of libation were the most important social practice in the Inka ceremonies, which involved the entire social group starting with the most important as rulers, deities and the "Yllapa" or bodies of the deceased considered as principal. It is in this context that the "Ushnu" was the appropriate setting for such rituals with a leading role, and this was perceived and described subtly Spanish colonial records. The study based on an analysis of historical sources, shows the detailed description of these places and the complexity and multifunctionality of the "Ushnu," in relation to the rituals of libation and ancestor worship by the Andean societies. It also raises the possibility of using a large number of the "Yllapa Usno" or receptacles for libations that might have a movable character, and every ancestor of every social group had to give theirs.
\end{abstract}

Keywords

Ushnu, Yllapa Usno, Ancestor, Ritual, Libation, Ethnohistory, Inka State.

* Licenciado en Arqueología, miembro del Programa de Estudios Andinos de la PUCP y de la Directiva de la organización WAMANI de Investigación y Puesta en Uso Social del Patrimonio Cultural.

Correo electrónico: josepinomatos@gmail.com / jose.pino@pucp.edu.pe 


\section{INTRODUCCIÓN}

El presente artículo es un conjunto de propuestas de interpretación en base a una sistematización y análisis de las referencias históricas sobre rituales de libación en relación al Ushnu, lugar que tuvo por principal función servir en las libaciones y que asimismo se consideró como un espacio específico con carácter de centralidad en todas las actividades y ceremonias públicas del estado Inka.

Los rituales de libación, en la época Inka, debieron ser la parte medular de toda negociación e inicio de alianzas para los fines estatales, y la bebida obviamente debió ser el elemento principal a ser consumido, é identificado como el insumo de mayor consideración en todas las fiestas, al menos así se percibió cuando llegaron los españoles, y los sacerdotes cristianos lo citan de esta manera:

"La principal ofrenda y la mejor, y la mayor parte de sus sacrificios, es la chicha por ella, y con ella comienzan todas las fiestas de las huacas, en ella median, y en ella acaban, sus fiestas, y ella es el todo. Y assí tienen para este efecto muchos vasos, y vasijas de diferentes formas, y materias, y es común modo de hablar, que dan de beber a las Huacas, quando les van a mochar" (Arriaga 1920:42 [1621: Capítulo IV]).

Impresionantemente esta cita sintetiza toda la importancia de la bebida fermentada de maíz conocida como chicha y consecuentemente de la acción de beber, no solo entre las poblaciones sino de beber con sus deidades que a su vez en muchos casos eran considerados sus ancestros, que ciertamente se tenía por asumido que las deidades si bebían lo que se les ofrecía.

Estos rituales de libación ya estaban muy bien identificados por los evangelizadores españoles en el siglo XVII, que incluso en los libros de sermones son especificados como por el famoso extirpador de idolatrías Francisco de Ávila cuestiona a la población indígena sus creencias diciendo: "Pues padre, ¿Cómo no nos das a entender una cosa de mucha dificultad? Los ingas y reyes antiguos, para haber de adorar el sol, ino le fabricaron una casa y templo en el Cuzco y allí no le sacrificaban con cuyes y carneros blancos y daban de beber chicha blanca, diciéndole: "Oh Sol, señor poderoso de barbas rubias, dame vida, porque tú eres el padre y criador de nosotros los ingas", y les suelen poner chicha blanca para que beba en una vasija muy grande de oro, poniéndola en la Casa del Sol para que, por una lumbrera entrando el rayo, diese en el vaso y entonces decían: "Ya bebe nuestro padre el Sol"? siendo esto así, ¿Cómo decís lo contrario?" (Ávila 2002: 50-51[1646]). Y definitivamente conocida la importancia de la libación, la evangelización católica tenía que reprender fuertemente estas prácticas ancestrales, indicando que la población indígena "como no tenían libros ni maestros que les enseñasen a conocer al verdadero Dios, por esto adoraron al sol, y el demonio, nuestro enemigo, los engaño para que adorasen las huacas, y los hechiceros, ministros del demonio, porque les daban de comer y de beber, les decían muchas fábulas y les ponían miedo, diciendo que, porque no ofrecían a sus huacas ni daban de beber a sus mallquis, por eso enfermaban y se les perdian sus ganados y sementeras" (Avendaño 2002:148 [1649]). Por lo tanto, el beber y brindar se consideró como la práctica esencial en las relaciones sociales no solo entre los vivos sino también con los ancestros.

Es en contextos similares, que años atrás a la conquista española, estratégicamente el estado Inka concentró la realización de múltiples actividades en los Ushnu, realzando de esta manera la importancia de este lugar, y distinguiéndose la libación como el acto más importante de casi todas las practicas sociales.

Es por ello que para tener un acercamiento más preciso a partir de la etnohistoria, se presenta aquí el estudio de algunos textos de testigos coloniales de los usos y costumbres de dos siglos posteriores al fin del Tawantinsuyu. Este análisis resulta muy útil para la comprensión de evidencias arqueológicas o la búsqueda de ellas, sobre todo si se investiga rituales Inka fuera del Cuzco. De esta manera, el estudio que aquí se presenta sobre espacios rituales, se orienta a en- 
tender espacios y construcciones ceremoniales construidas a partir de la época Inka e inmediatamente posteriores a ella.

Este estudio por lo tanto, presenta de forma específica, las evidencias encontradas en los documentos coloniales de los siglos XVI-XVII y los resultados de los vínculos del Ushnu en torno a los rituales de libación con sus características detalladas, de la siguiente manera:

- Evidencias encontradas en el registro etnohistórico.

- La denominación del Ushnu, con sus diferentes términos y palabras quechua.

- El contexto general del Ushnu, indicando sobre la mención de lugares o provincias donde estos encontraban, los personajes asociados a este lugar y a los rituales de libación, las deidades asociadas, el marco temporal de uso, y qué tipo de lugar eran considerados.

- El Ushnu como Instalación Ritual, indicando sobre su ubicación espacial, el tipo de construcción, descripciones y morfología, el material de construcción, sus instalaciones con propósitos particulares, los monumentos y construcciones asociados a este, los sistemas de acceso y desplazamiento, las divisiones y distribución de los participantes en los rituales de libación en torno a él, y el posicionamiento de los personajes sobre el mismo.

- Las Actividades realizadas en los Ushnu, indicando las acciones ceremoniales y religiosas, las acciones sociales y políticas, las acciones militares, y las acciones tecnológicas y astronómicas que se llevaban a cabo.

- Los Objetos rituales asociados al Ushnu, indicando sobre los bienes consumidos $\mathrm{u}$ ofrendados, los bienes utilitarios asociados y los objetos con significado simbólico.

Como se dijo, el estudio se orienta a entender los espacios aun existentes de la época Inka que pudieron haber servido en los rituales hace
500 años atrás, por lo que para un estudio más detallado de las fuentes, se ensayó aplicar ciertas perspectivas de análisis planteadas por Rafael Vega-Centeno para el estudio arqueológico del ritual (Vega-Centeno 2006: 171-192), que al aplicarlo al estudio de fuentes históricas brindó interesantes propuestas de interpretación. A continuación aquí se presenta los resultados de esta investigación.

\section{El USHNU, LIBACIONES Y RITUALES EN EL REGISTRO ETNOHISTÓRICO. LAS EVIDENCIAS COLONIALES DE LOS SIGLOS XVI-XVII}

Para el presente estudio se revisaron solo 31 fuentes coloniales, en las que se hizo una búsqueda del término quechua "Ushnu" y términos similares, así como referencias relacionadas a este término. Se utilizó 84 citas relacionadas a la búsqueda. A continuación se presentan las evidencias en orden cronológico de publicación:

\section{[1534] Pedro Sancho de la Hoz:}

1. "En medio de ella hay dos isletas pequeñas, y en una hay una mezquita y casa del sol que es tenida en gran veneración, y a ella van a hacer sus ofrendas y sacrificios en una piedra que está en la isla que se llama Tichicasa, en donde, o porque el diablo se esconde allí y les habla, o por costumbre antigua como es, o por otra causa que no se ha aclarado nunca, la tienen todos los de aquella provincia en grande estima, y el ofrecen oro, plata y otras cosas. Hay más de seiscientos indios sirviendo en este lugar, y más de mil mujeres que hacen chicha para echarla sobre aquella piedra Tichicasa" (Sancho de la Hoz 1968:331-332 [1534: Capitulo 18]).

\section{[1545] Juan de Ruiz de Arce:}

2. "En el medio del monasterio está un patio grande; en el medio del patio está una fuente y junto a la fuente está un escaño. Este escaño era de oro, pesó dieciocho mil castellanos. Junto al escaño estaba un ídolo. A mediodía quitaban 
el cobertor que tenía el escaño, llevaba cada monja un pato de maíz y otro de carne y otro de un jarro de vino, y ofrecíanlo al ídolo. Y desque habian acabado todas de ofrecer sus sacrificios, venían dos indios, que tenían cargo de aquello, que traían un brasero de plata, grande, encendido; echaban el maíz y la carne, y el vino echábanlo en la fuente. De que acaban de quemar, hacían su sacrificio y alzaban las manos al sol y dábanle gracias. En esta tierra adoran al sol" (Ruiz de Arce 1968:432 [1545]).

\section{[1551] Juan de Betanzos:}

3. "Y llegado el Ynga ofrecíanle aquel vestido y el Ynga lo rescibía y luego se lo vestía y se ponía su cabellera y parescía natural de aquella provincia y ansi entraba en el pueblo principal della donde llegado que era a la plaza del le tenían hecho cierto asiento a manera de un castillejo alto y en do medio del castillejo una pileta llena de piedras y como llegase el Ynga al pueblo subíase en aquel castillejo y allí se sentaba en su silla y de allí veía a todos los de la plaza y ellos le veían a él y siendo allí traían delante del muchos corderos y allí se lo degallaban delante y se los ofrecían y luego le vaciaban delante mucha chicha en aquella pileta que allí estaba en sacrificio y él bebía con ellos y ellos con él" (Betanzos 1987:185 [1551]).

4. "Y esto ya todo junto Ynga Yupangue mandó hacer un gran fuego en el cual fuego mandó después de haber hecho degollar las ovejas e corderos que fuesen echadas en él y las demás ropa y maíz ofreciéndolo todo al sol e los niños e niñas que ansi habian juntado estando bien vestidos e aderezados mandólos enterrar vivos en aquella casa que en especial era hecha para do estuviese el bulto del sol" (Betanzos 1987:51 [1551]).

5. "Y allí luego mandó que todos los de la ciudad ansi hombres como mujeres viniesen a hacer sus sacrificios allí a la casa del sol los cuales sacrificios que ansi la gente común hizo fue quemar cierto maíz e coca en aquel fuego que ansi era hecho entrando cada uno destos uno a uno y descalzos los ojos bajos" (Betanzos 1987:51 [1551]).

6. "en el cual escaño puso Ynga Yupanga el bulto del ídolo y siendo allí puesto hizo traer un brasero de oro e siendo encendido en el fuego mandóle poner delante del ídolo en el cual fuego e brasero hizo hechar ciertos pajaricos e ciertos granos de maiz e derramar encima de tal fuego cierta chicha todo lo cual dijo que comía el sol e que haciendo aquello le daba a comer e de allí adelante se tuvo aquella costumbre ordinariamente lo cual hacía aquel mayordomo del sol" (Betanzos 1987:52 [1551]).

7. "Y para en que la gente común adorasen allá fuera porque no habían de entrar alli si no fuesen señores y éstos en el patio hizo poner en medio de la plaza del Cuzco donde ahora es el royo una piedra de la hechura de un pan de azúcar puntiaguda para arriba y enforrada e una faja de oro la cual piedra hizo ansi mismo labrar el día que mandó hacer el bulto del sol y ésta para en que el común adorase y el bulto en las casas del sol los señores" (Betanzos 1987:52 [1551]).

8. "y el día que el ídolo se puso en las casas del sol se puso la piedra en medio de la plaza e dende a diez días que el bulto fue puesto en el escaño que habéis oído" (Betanzos 1987:53 [1551]).

9. "Y le hacían sacrificio delante al cual sacrificio llaman ellos Arpa y lo que le daban para comer y servicio que le hacían todo era en aquella solemnidad como que hacian sacrificio a sus idolos" (Betanzos 1987:53 [1551]).

10. "Y al poner que la piedra se puso en medio de la plaza del Cuzco hízose en ella un gran hoyo primero donde todos los de la ciudad chicos y grandes ofrescieron al sol las piezas de oro que les pareció y esto ofrecido cerraron el hoyo encima del cual hicieron y edificaron una pila de cantería de altor de medio estado y en la redondez de la pila enterraron unos bultos de oro de largor de un dedo y del mismo gordor cada uno y estos bulticos que ansi enterraron en torno de la pila" (Betanzos 1987:53 [1551]). 
11. "Ansi hechos y puestos en esta orden los metieron debajo de la tierra de dentro de la pila arrimados a las paredes dellas y en medio de la pila pusieron la piedra que significaba el sol y este meter de estos bulticos ansi en torno della era un ofrecimiento que hacían al sol de la generación de los del Cuzco y de los linajes della desde que Mango Capa la había poblado hasta los que en aquel tiempo eran" (Betanzos 1987:53 [1551]).

12. "Y puesta la piedra y los bulticos en la manera que habéis oído todos los de la ciudad le hicieron sacrificios de mucha y gran cantidad de ovejas y corderos y desde entonces hasta que los españoles entraron en la ciudad del Cuzco siempre los naturales de la ciudad acostumbraron a hacer este sacrificio a este ídolo en piedra e fueron tantas las ovejas e corderos que alli a aquel ídolo sacrificaron desde que le pusieron hasta que los españoles entraron en la ciudad que no lo saben ni pueden numerar lo mas que icen que la vez que menos ovejas y corderos allí se sacrificó que pasan más de quinientos" (Betanzos 1987:53 [1551]).

\section{[1553a] Pedro Cieza de León:}

13. "Y los reyes, para que en la guerra, siendo muchos no se enbaraçasen tenían esta orden: que en la gran plaça de la çibdad del Cuzco estava la piedra de la guerra que era grande, de la forma y hechura de un pan de açucar, bien engastonada y llena de oro" (Cieza de León 1986:69 [1553: fol.30v.]).

14. "Y en mitad de la plaça tenían puesto, a lo que dizen, un teatro grande con sus gradas, muy adornado con paños de pluma llenos de chaquira de oro y mantas grandes riquísimas de su tan fina lana, senbradas de argentería de oro y de pedrería. En lo alto deste trono ponían la figura de su Tiçiviracocha, grande y rica; al qual, como a quien ellos tenían por dios soberano hacedor de lo criado, lo ponían en lo más alto y le davan el lugar más eminente y todos los çaçerdotes estaban junto a él" (Cieza de León 1986:91 [1553: fol.38v.]).

\section{[1553b] Pedro Cieza de León:}

15. "Y en otra piedra no pequeña, que está en este tiempo en mitad desta plaça a manera de pila: donde sacrificauan y matauan los animales $y$ niños tiernos (a lo que dizen) cuya sangre ofrescían a sus dioses" (Cieza de León 1995:252 [1553: fol.115v.]).

16. "Y en medio de la gran plaça auía otro escaño a manera de teatro, donde el señor se assentaua para ver los bayles y fiestas ordinarias" (Cieza de León 1995:252 [1553: fol.115v.]).

17. "Lo qual hecho, vierten muchas vasijas de su breuaje por las mismas sepulturas, y con ello dan fin su costumbre tan ciega y vana" (Cieza de León 1995:277 [1553: fol.126v.]).

\section{[1553] Cristóbal de Molina, el Chileno 1968:}

18. "y en cada pueblo, plaza grande real y en medio de ella un cuadro alto de terraplen, con una escalera muy alta: se subian el Inca y tres señores a hablar al pueblo y ver la gente de guerra cuando hacían sus reseñas y juntas" (Molina 1968: 316 [1553]).

\section{[1560] Fray Domingo de Santo Thomas:}

19. "Altar donde sacrifican osño, o coconga pac" (Santo Thomas 2006:474 [1560:f9v.]).

20. "Ozño, o osño altar, o ara para sacrificar" (Santo Thomas 2006:157 [1560:f9v.]).

21. "Osño, o cocongapac altar, donde sacrifican" (Santo Thomas 2006:599 [1560:f157v.]).

\section{[1561] Bartolomé de Las Casas:}

22. "Estos sacrificios se ofrecían en los templos principales el Sol cada día, quemando todas aquellas cosas los sacerdotes que estaban deputados para ello. También ofrecían de sus vinos en mucha cantidad, y ofrecianlo desta manera: que tenían en los pueblos una pileta de piedra muy linda, debajo de la cual había un sumide. 
ro, donde lo derramaban y se consumía" (Las Casas 1892: 58 [1561]).

23. "En el Cuzco había casas del Sol que eran muy bien labradas de cantería y cercadas junto a la techumbre de una plancha de oro de palmo y medio de ancho, lo mismo tenían por de dentro en cada bohío o casa y aposento. Tenía el primer patio una grande pila de piedra, bien hecha, donde ofrecian chicha, ques un brevaje hecho de maíz, a manera de cerveza, diciendo quel Sol bajaba alli a beber" (Las Casas 1892: 132 [1561]).

\section{[1565] Anónimo:}

24. "Es ansi, que, para tomar el punto del Sol, entre los dos pilares de en medio tenían otro pilar en medio de la plaça, pilar de piedra muy labra$d a$, de un estado en alto, en un paraje señalado al propósito, que le nombraban Osno, y desde allí tomauan el punto del Sol en medio de los dos pilares, y estando ajustado, hera el tiempo general de sembrar en los valles del Cuzco y su comarca" (Anónimo 1906:151 [Ca. 1565]).

25. "La Luna del mes de setiembre llamauan Cituaquilla. Este mes se juntauan en el Cuzco todos los yndios de toda la comarca, y juntos todos en la plaça principal, llamada Haocaypata, $y$ alli hazían sus sacreficios al Sol con muchas ceremonias, en un pilar de piedra que tenían en medio de la plaça, con su treatro llamado Osno, y los hazian de corderos y rropas de precio y otras muchas cosas, y al pie del treatro vertían mucha chicha; dezían que la ofrescían al Sol" (Anónimo 1906:158 [Ca. 1565]).

\section{[1570] Inga Diego de Castro Titu Cusi Yupanqui:}

26. "Los españoles con gran furia arremetieron al medio de la plaça donde estava un asyento del ynga en alto a manera de fortaleza, que nosotros llamamos usnu, los cuales se apoderarón dél y no dexaron subir alla a mi tio, mas antes al pie dél le derrocaron" (Titu Cusi Yupanqui 1992:7 [1570: fol. 4r-4v]).

\section{[1571] Pedro Pizarro:}

27. "Tenían también delante destos muertos unos cangilones grandes que ellos llamaban verquis de oro o de plata o de barro, cada uno como querían, y aqui echaban la chicha que al muerto le daban mostrándosela, convidándose unos muertos a otros, y los muertos a los vivos y los vivos a los muertos. Pues llenos estos verquis los derramaban en una piedra redonda que tenían por ídolo, en mitad de la plaza, y hecho alrededor una alberca pequeña a donde se consumía por unos caños que ellos tenían hechos por debajo de tierra" (Pizarro 1968:495 [1571]).

28. "Todas estas cenizas que quedaban de estos fuegos que hacían, las echaban en este pilón que digo estaba en mitad de la plaza y piedra redonda a manera de teta, donde echaban [la chicha]" (Pizarro 1968:496 [1571]).

\section{[1572] Pedro Sarmiento de Gamboa:}

29. "Y asistiendo un día a ver cómo las mamaconas servían la comida al Sol-que era ofrecelle muchos manjares guisados a la estatua e ídolo del Sol, y después lo echaban allí delante en un gran fuego, que en un ara a manera de altar tenían, y por la mesma orden la bebida, la cual, haciendo la mayor de las mamaconas la salva al Sol en un pequeñito vaso, echaba lo demás en el fuego, y tras esto echaban muchos cantaros de aquel brebaje en una pila que tenía un sumidero, todo ofreciéndolo al Sol, y este servicio se hacía con vasos de barro-, y como Pachacuti considerase la pobreza de la vasija, dióle todo el servicio que era menester, muy cumplidamente , de plata y oro" (Sarmiento de Gamboa 1943:187 [1572: Cap. 36]).

\section{[1575] Cristóbal de Molina, el Cusqueño:}

30. "Y en la plaza en medio della, ado estaua el usño de oro, que hera a manera de pila a donde hechauan el sacrifiçio de la chicha quando ueuian, hallauan que estauan a punto de guerra quatroçientos yndios alrrededor de la dicha pila" (Molina 2008:155 [1575: fol. 11v.]). 
31. "Dauan aquel día gracias al haçedor por los auer dejado llegar aquella fiesta y que los llegase a otro año sin enfermedades y lo mesmo al sol y trueno beuia el ynca con ellos tenía el sol delante de si un uasso de oro grande en que echaua el ynca chicha de alli el sacerdote se le tomaua y la hechaua en el usño que como dicho es es a manera de pila de piedra enforrada en oro la qual tenia un abujero hecho de tal manera que llegaua a un albañar el caño que yba por debajo de tierra hasta las cassas del sol y el trueno y el Hacedor los sacerdotes dellos ueuian unos con otros y los cuerpos embalsamados" (Molina 2008:160 [1575: fol. 14r.]).

\section{[1582] Cristóbal de Albornoz:}

32. "Hay otra guaca general en los caminos reales y en las plazas de los pueblos, que llaman uznos. Eran de figura de un bolo hecho de muchas diferencias de piedras o de oro y de plata. A todos les tenían hechos edificios en donde tengo dicho en muchas partes como en Bilcas y en Pucara y en Guanaco el Viejo y en Tiaguanaco, a hechura de torres de muy hermosa cantería. Sentávanse los señores a bever a el sol en el dicho uzno y hazian muchos sacrificios a el sol" (Albornoz 1967: 24 [1582]).

33. "Usno era un pilar de oro donde bevían al sol en la plaza" (Albornoz 1967: 26 [1582]).

34. "Hay otros géneros de guacas que se llaman illapas, que son cuerpos muertos embalsamados de algunos pasados suyos principales, a los cuales reverencian y mochan" (Albornoz 1967: 19 [1582]).

\section{[1584] Cristóbal de Albornoz:}

A continuación citaremos los casos que Albornoz refiere en su destrucción de Huacas, descrito en el documento sobre "Las guacas adoratorios e ydolatrias que se hallaron en este curazgo de los Soras" (Albornoz 1990: 264 [1584: fol. 47v.]) refiere que se descubrió y quemo muchos ídolos y huacas entre ellas las que pertenecían a:
35. El cacique Pedro Caquia Llamoca algunas eran: "... diez y seis Yllas, quatro mamasaras, dos vilcas, ocho Yllapas, usnos, tenian sus ropillas y otras inmundicias" (Albornoz 1990: 265 [1584: fol. 48r.]).

36. El cacique Fernado Gualca Guamani algunas eran: "...diez Yllas, una mamasara, dos Vilcas, Cotan Vilca, Chupamarca, Ají, Anta Guaico, Guancani, Guachualla, Choconalla, dos Yllapas, Usnos, nueve charpas, ocollaguaca e una pluma de halcón" (Albornoz 1990: 265 [1584: fol. 48r.]).

37. Don Francisco Usco algunas eran: “...seis Yllas, dos Yllapas, Chuquironto, dos Yllapas, Usnos, tres Vilcas..." (Albornoz 1990: 266 [1584: fol. 48v.]).

38. Don Fernando Quispe algunas eran: “...tres Vilcas, seis Llama-yllas, siete Yllapas, Usnus Charcana" (Albornoz 1990: 267 [1584: fol. 49r.]).

39. Don Joan Pujaico algunas eran: “...seis Vilcas, cincuenta Lamaylas, y diez Mamasaras, onze Yllapas, Oznos, Guaman ynga, que es una pluma de halcón" (Albornoz 1990: 267 [1584: fol. 49r.]).

40. Don Gonzalo Chancanaupa algunas eran: “...Pomas, Arapito, tres Yllapas, Osnos, tres Vilcas, tres mamasaras, veinte Yllas" (Albornoz 1990: 267 [1584: fol. 49r.]).

41. Don Antonio Yanquemalco algunas eran: “...doze Yllas, veinte y una Mamasaras, tres Coror,Ylla, quatro Vilcas; y junto a estas avía munchas Yllapas Usnus; fueron casi todas ellas traydas ante el señor Vistador y por su mandado se quemaron públicamente según que las demás" (Albornoz 1990: 267 [1584: fol. 49v.]).

42. Don Alonso Asto Guaraca algunas eran: "...quatro Llamaylas, dos Mamasaras, una Yllapa, Usno” (Albornoz 1990: 268 [1584: fol. 49v.]).

43. De los caciques del pueblo de Chinchera algunas eran: "...Gual Villani, siete Yllapas, 
Usnos, Rupay, Agualla" (Albornoz 1990: 274 [1584: fol. 54r.]),

44. “...Hanco Caua, Gualpa Viri, treze yllapas, usnos, ochenta llama yllas, cinco mamazazas, cinco Vilcas,..." (Albornoz 1990: 274 [1584: fol. 54v.]).

45. De los caciques del pueblo de Chicha algunas eran: "...Taxcarima, Apaxallaquio, Caxapi Guazmi, Ochuylla Poboznos (ocho yllapob oznos), siete llamayllas, tres mamasaras, una Vilca" (Albornoz 1990: 275 [1584: fol. 54v.]).

46. De Don Alonso Espilco principal del pueblo de Matara algunas eran: "...Guacho Canchoni, Puquio Guacani, e cinco guacas que estavan en Choconapi, diez y nueve Yllapas, usnos, todas las que se pudieron traer se traxeron..." (Albornoz 1990: 275 [1584: fol. 55r.]).

47. De Martín Taype Marca del pueblo de Marquilla algunas eran: "...Quirochani, dies Yllpas, Usnos, una Bilca” (Albornoz 1990: 275 [1584: fol. 55r.]).

48. Don Alonso Alvarado Guacralli del pueblo de Hanansora algunas eran: "...Yncallalla, Usco, cinco Yllapas, Usnos, Guasuca, Guasucatapi, Chullpuyo, Lacaya Villuchi, Huirtoma, Chupapacta, Uniaricata, Callicata, Lacta Atacara, Guamanicasa, Capaccocha, dos llama yllas, una mamazaza, dos Vilcas" (Albornoz 1990: 276 [1584: fol. 55r.-55v.]).

49. Don Baltasar Guaman Llamoca principal de Lurinsora algunas eran: “...Pamuta, Cocha Guachota, tres yllapas, usnos, dos llamayllas, una mamazaza,..." (Albornoz 1990: 276 [1584: fol. 55v.]).

50. Don Joan Soraya algunas eran: “...Yllay Curi, Viri Cunicama, y más veinte Guaquillas que estavan juntas Capaccocha, otra Capaccocha Caruaraco, dos yllapas, usnos, veinte llamas yllas, una mmazara, quatro Vilcas, ..." (Albornoz 1990: 276 [1584: fol. 55v.]).

51. "Ansimismo paresçe fueron halladas y descu- biertas las guacas de Pedro Alonso Pariona, y Alonso Martín Yauricopa, y don Antonio Aymas Y oznos, que fueron más de noventa, donde abía yllapas, relámpagos, truenos, que por sus nombres están asentados en la visita, y se quemaron por mandado del dicho señor canónigo siendo visitador" (Albornoz 1990: 287 [1584: fol. 63r.]). Estas huacas adoratorios se hallaron en los cacicazgos de Anan Lucanas.

\section{[1585] Blas Valera:}

52. "Deste género de templos naturales usaron los peruanos mucho tiempo sin hacer edificio alguno, y cuando mucho, hacían en los tales lugares un altar de piedra, que llamaban osno, para sus sacrificios" (Valera 1945:12 [1585]).

\section{[1591] Reginaldo de Lizárraga:}

53. "La piedra, es durisima y el edificio fijisimo, que para romperlo se pasa mucho trabajo. Permanece en nuestro convento una pila grande desta piedra, ochavada por de fuera, que de hueco debe tener, por cualquiera parte que la midan, mas de vara y media, y de fondo mas de vara y cuarta. A esta pila hinchian con cantidad de chicha, escogida de la que el Inga bebia, para que bebiese el Sol, y lo que en ella se embebia creia esta gente barbara que el Sol lo bebia; cubria la boca desta pila una lamina de oro, en la cual estaba el Sol esculpido. Cuando los españoles entraron en esta ciudad le cupo en suerte a uno de los conquistadores, que yo conoci, llamado Mansio Sierra, de nacion vizcaino y creo provinciano, gran jugador; jugo la lamina y perdiola: verificose en el que jugó el Sol" (Lizárraga 1916: 198-199 [1591: Cap. 80])

\section{[1608] Diego Gonzales Holguín:}

54. "Vsnu. Tribunal de juez de una piedra hincada; Vsnu. Mojón quando es de piedra grande hincada; Vsnuni. Hazer los tribunales, o mojones" (Gonzales Holguín 1989:358 [1608]). 


\section{[1608]Manuscrito de Huarochirí:}

55. "Antiguamente, cuando se celebraba la llegada de Llocllayhuancupa, los hombres que participaban en el rito bailaban hasta la puesta del sol. Cuando ya se acercaba la noche, su sacerdote decía: Nuestro padre ya esta borracho; ique baile! Y bailaba en su lugar el baile llamado Ina. "Nuestro padre os convida", decía y traía chicha en un quero minúsculo. Ponía otro en una olla que se encontraba en el interior del santuario diciendo: "Es él quien bebe". Hacía beber a todos los presentes empezando por los más ancianos. Se dice que, cuando terminaba de servirles la chicha, llevaba el mate en el que el demonio había bebido afuera para que los que habían sido convidados a beber lo adorasen" (Taylor 2003:101-102 [1608])

56. "Lo sirvieron de esa manera muchos años. Una vez, quizás porque no lo servían bien, llocllayhuancupa desapareció y volvió donde su padre Pachacamac. Al darse cuenta, la gente, muy afligida, lo busco y embelleciendo el sitio en donde Lantinchumpi lo había encontrado por primera vez, le construyo un usno" (Taylor 2003: $92-93$ [1608]).

\section{[1609] Inca Garcilaso De la Vega:}

57. "Hecho el convite del beber derramaba el vaso de la mano derecha, que está dedicado al sol, en un tinajón de oro. Y del tinajón salía a un caño de muy hermosa cantería que desde la plaza mayor iba hasta la casa del sol, como que él se lo hubiese bebido. Y del vaso de la mano izquierda tomaba el Inca un trago, que era su parte" (Garcilazo de la Vega 1991:372 [1609:lib.6, Cap. 21]).

\section{[1609] Carta Annua:}

58. "ofrecen al ídolo vnos mates de chicha rogándole que los beua. y derramándolos en señal de que el ídolo los beue. comienzan ellos a beuer" (Taylor 2000:83 [1609]).

\section{[1612] Ludovico Bertonio:}

59. "Altar de las guacas, hecho de piedras labradas, como se ve en las punas. Husnu" (Bertonio 2006:77 [1612])

\section{[1613] Joan de Santa Cruz Pachacuti Yamqui Salcamayhua:}

60. "y cuando quería hacer conquistas enviaba a sus capitanes y gente, a los cuales dicen que en cada quebrada les hacía llevar piedras para hacer usnus q son unas piedras puestas como estrado" (Santa Cruz Pachacuti 1995:22 [1613: fol. 9v.]).

61. "al fin llega a Guamañin mas aca de Villcas en donde la primera vez lo abía visto La mala visión de siete guacas y en çima de aqueel osno de guamani entierra mojones de oro y plata en memoria de lo que vençio y prendió mane atándoles a los dichos ydolos y diablos q abia benido en figura de yndios muy grandes" (Santa Cruz Pachacuti 1995:64 [1613: fol. 21r.]).

62. "después de tres días con la misma fiesta y solemnidad en el mismo lugar donde los casso y los entrega el Capac unancha para q los lleuase adelante al vsno y entrega lo mismo a guaman champi de dos bocas o filos con sus adargas o vallcancas" (Santa Cruz Pachacuti 1995:92 [1613: fol. 31v.-31r.]).

63. "y tras desto todos en general los alaba al hacedor pacha yachic viracochan assi llamado y les Ruega por su salud etc y después de aber acabado trae a la plaza de haocay pata y en donde tenía su capac vsno como en villcas y se asienta allí y assi dizen que todos los grandes y capitanes dan obediencia cada vno con su gente hechos de los infieles" (Santa Cruz Pachacuti 1995:92 [1613: fol. 32r.]).

64. "Y para ello manda que en cada quebrada obiesen vsnos para ver si yban con buena orden de guerra y en cada guamanin de treinta leguas los visita que numero de gente lleua cada capitán" (Santa Cruz Pachacuti 1995:92 [1613: fol. 33v.]). 
[1615] Felipe Guaman Poma de Ayala:

65. "Que los Yngas tienen tierra señalado en todo este rreyno para sacrificios llamado usno, que es para sacrificar cienpre capa cocha al sol y a las uacas, uaca caray, al caminar apachito. Es la ley y sacrificio de los Yngas" (Guaman Poma 1987:254 [1615: fol. 262[264]]).

66. "Pacha Cuti Ynga dio orden muy mucha hazienda para sacrificar a las uacas y de las casas del sol y tenplo de Curi Cancha; el trono y aciento de los Yngas llamado usno en cada wamani señaló" (Guaman Poma 1987: [1615: fol. 265 [267]])

67. "Trono y aciento del Ynga, llamado usno, en el Cuzco" (Guaman Poma 1987:406-407 [1615: fol. 398[400]]). (Ver Fig. 1)

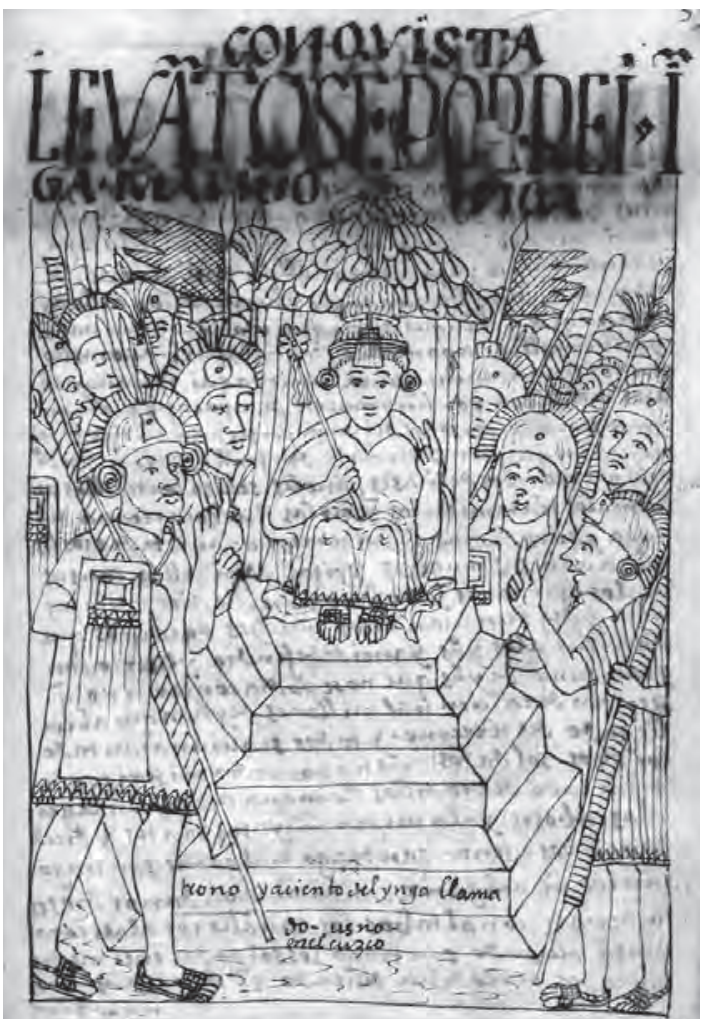

Figura 1: El Inka en el Ushnu según

Felipe Guaman Poma de Ayala (1987 [1615]).

68. "Conquista, Atagualpa Inga está en la Civdad de Caxamarca en sv trono Vsno, Almagro, Pi- zarro, Fray Uisente, Felipe, yndio lengua, usno, asiento del Ynga, ciudad de Caxamarca, Se acienta atagualpa Inga en su trono" (Guaman Poma 1987:390-391 [1615: fol. 384[386]]).

69. "Y llegado con su magestad y sercado de sus capitanes con mucho más gente doblado de cien mil yndios en la ciudad de Caxamarca, en la plasa pública en el medio en su trono y aciento, gradas que tiene, se llama usno, se asentó Atagualpa Ynga" (Guaman Poma 1987:392 [1615: fol. 385[387]]).

70. "Cómo le rrecibieron en la ciudad de Guamanga y dallí se fue hacia la ciudad del Cuzco y llegó a Bilcas Guaman y subió al aciento y gradas, usno del Ynga, y ancí fue rreciuida como el mismo Ynga todos los señores principales. Y mandó subir al más viejo y principal al usno, a don Alonso Naccha Uarcaya del pueblo de San Pedro de Queca de la prouincia de los Lucanas, Andamarcas, Soras" (Guaman Poma 1987:452 [1615: fol. 445[447]]).

\section{[1615] Fray Martín de Murúa:}

71. “....en torno de Tomebamba, ...y demás de esto puso la Huaca principal que ellos tenían en mayor veneración y respeto acá en el Cuzco, llamada Huana Cauri, y demás de esto todas las demás Huacas que tenían alrededor del Cuzco, todas por su orden y traza como estaban en el Cuzco. Hizo el edificio en la plaza para el usmo que llaman los indios Chuqui pillaca, para sacrificar la chicha al sol cuando bebían con él" (Murúa 2001: 103 [1615: Libro I, Capitulo 31]).

\section{[1621] Rodrigo Hernández Príncipe:}

72. "Hacíanle chácaras para sus fiestas de entre año, degollaban los cuyes y de un usnu, que es un arcadus, que deshicimos en este lugar, le daban de beber, invocándola y diciendo: "Ven aquí con tu padre Caque Poma"." (Hernández Príncipe 2003:745 [1621]).

73. "Entraban por la plaza estando el Inga en él sentado en su dúo de oro: por su orden las esta- 
tuas del Sol, Rayo, Trueno y los ingas embalsamados con los sacerdotes que les manifestaban" (Hernández Príncipe 2003:743 [1621]).

74. "Brindaba el Inga al Sol de una chicha de muchos años, hecha para esta ocasión, que la coya, con acompañamiento de las pallas, había traído en dos aquillas de oro; y la chicha que brindaba al Sol, volvía vacía, por orden del demonio para atraer a la creencia del Sol a todo un reino que estaba allî" (Hernández Príncipe 2003:743 [1621]).

\section{[1621] Alonso Ramos Gavilán:}

75. "Assí se vee oy delante de la peña por assiento una Cruz, que allí está puesta, una piedra redonda, a la traça de una vasija en que echavan la chicha, que avía de beber el Sol, no sé con qué instrumento se labró, porque está con extremo bien acabada" (Ramos Gavilán 1988: 116 [1621:lib.1, cap. 17]).

\section{[1649] Pedro de Villagomez:}

76. "Y diciendo estas cosas, y otras semejantes, derrama la chicha delante de la huaca, y a veces encima della, y otras la asperja con ella, como quien da papirotes" (Villagomez 1919:157 [1649: Capitulo 44]).

77. "La principal ofrenda, y la mejor y la mayor parte de sus sacrificios es la Chicha. Por ella y con ella comienzan todas las fiestas de las huacas, en ella median, y con ella acaban; y assí tienen para este efecto muchos vasos y vasijas de diferentes formas y materias; y es común modo de hablar, que dan de beber a las huacas cuando les van a mochar" (Villagomez 1919:163 [1649: Capitulo 45]).

\section{[1653a] Bernabé Cobo:}

78. "Delante de la dicha peña y altar se ve una piedra redonda al modo de bacia, admirablemente labrada, del tamaño de una piedra de molino mediana, con su orificio, que ahora sirve al pie de una cruz, en que echaban la chicha para que el sol bebiese" (Cobo 1956:193 [1653: Libro 13, Capitulo 18]).

\section{[1653b] BernabéCobo:}

79. "[An-5:1] la primera era una piedra llamada, vsno, que estaua en la plaza de Hurin aucaypata; era esta la primera Guaca a quien ofrecían los que se hacían orejones" (Cobo 2003:202 [1653]).

80. "[Cu-14:1] la primera era una piedra no mui grande llamada, oznuro, que estaua en la chacara de los Gualparocas" (Cobo 2003:213 [1653]).

\section{[1657] Bernardo de Noboa Sotela:}

81. "Y asi mesmo dijo que en el asiento de chacras llamado tauya en medio del esta vna cancha corralito pequeño llamado osno y allí a mochado este testigo todos los años antes de empezar aser las chacras y que le a serbido de sachristan administrando las ofrendas Alonso chaupis siego y solian sacrificar llamas cuyes coca y sebo para tener buenas chacras y cosecha y que en la dicha cancha ai dos malquis llamados yanayacallua Libia y yana yacolca libia que están por sacar" (Noboa 2003:351 [1657: fol. 19v.]).

82. "Y asi mesmo que el dicho su padre en vn corralito que está en medio de las chacras que llaman Husnu al prinsipio tanbien de las primeras aguas degollaba vn cui blanco y con la sangre con los mesmos dedos asperjaba al sol y le ofresia coca y se tiraba las pestañas lo qual hasia luego que rayaba el sol por la mañana y le pedia le diese comidas vida y buenas chacras de mais y coca y lo mesmo pedia a los malquis cuando los mochaba" (Noboa 2003:429 [1657: fol. 63v.]).

83. "y cuando se sentaban a beber en las fiestas en las plazas de los dichos pueblos los beia derramar chicha y coca que era la adicion con que mochaban a los ydolos" (Noboa 2003:331 
[1657: fol.6]).

84. "y el mismo dia que hasian la fiesta a los dichos sanctos quando se juntaban todos los pueblos en la plasa a comer y beber este testigo y todos los demás ministros de ydolos hasian a todos que de los primeros mates que empesaban a beber derramasen un poco de chicha soplándola y disiendo A señores malquis y señoras guacas y señores aguelos nuestros que estais en las yglesias bebed primero esta chicha antes que nosotros bebamos porque esta fiesta se hace a onrra vuestra" (Noboa 2003:335 [1657: fol. 10]).

\section{LA DENOMINACIÓN DEL USHNU}

\section{Términos y palabras quechua}

Curiosamente ninguna fuente histórica menciona la palabra quechua Ushnu, palabra que es usada por los arqueólogos a partir del siglo XX para designar a las plataformas en el centro de las plazas de sitios Inkas. Sin embargo por motivos de evitar confusiones, seguiremos usando la palabra Ushnu para referirnos al espacio, lugar o estructura donde se realizaban los rituales públicos específicamente los de libación, que es nuestro objeto de estudio.

Las descripciones más tempranas sobre importantes lugares de libación son mencionadas en los textos a partir de 1534. Sin embargo sobre la denominación de Ushnu o palabras similares no encontramos menciones literales tempranas, sino hasta 1560, coincidentemente en años posteriores al primer concilio limense reunido en 1551, en el que la practica social del culto de los ancestros de las poblaciones andinas es vista como contradictoria a la fe cristiana y católica de los españoles. Por lo que hay un afán de conocer sobre estas prácticas religiosas andinas antiguas pero con fines evangelizadores, por lo que a partir del primer concilio limense, quedan registrados de forma específica en los textos, léxicos y vocabularios, las palabras quechua vinculadas a lo que se consideraba cultos indígenas e idolatrías.

Es así que el primero en mencionar a los lugares de culto y sacrificio con nombre propio es
Fray Domingo de Santo Thomas, con la denominación de:

- Osño (Santo Thomas 2006:474 [1560:f9v.]; Santo Thomas 2006:599 [1560:f157v.]) y,

- Ozño (Santo Thomas 2006:157 [1560:f9v.]) termino que es igual a,

- Cocongapac (Santo Thomas 2006:474 [1560:f9v.]) (Santo Thomas 2006:599 [1560:f157v.]) como el lugar donde "dar" el sacrificio, equivalente según Santo Thomas a Osño.

Las siguientes denominaciones quechuas identificadas, referidas a las diferentes funciones del Ushnu serían:

- Osno (Anónimo 1906:151 [Ca. 1565]; Anónimo 1906:158 [Ca. 1565]; Valera 1945:12 [1585]; Santa Cruz Pachacuti 1995:64 [1613: fol. 21r.]; Noboa 2003:351 [1657: fol. 19v.]).

- Usnu (Titu Cusi Yupanqui 1992:7 [1570: fol. 4r-4v]; Santa Cruz Pachacuti 1995:22 [1613: fol. 9v.]; Hernández Príncipe 2003:745 [1621]).

- Vsnu (Gonzales Holguín 1989:358 [1608]).

- Usnuni para la acción de hacer un Usnu (Gonzales Holguín 1989:358 [1608]).

- Usño (Molina 2008:155 [1575: fol. 11v.]; Molina 2008:160 [1575: fol. 14r.]).

- Uznos (Albornoz 1967: 24 [1582]; Albornoz 1967: 24 [1582]).

- Usno como la grafía más mencionada por diferentes autores (Albornoz 1967: 26 [1582]; Taylor 2003: 92-93 [1608]; Santa Cruz Pachacuti 1995:92 [1613: fol. 31v.31r.]; Santa Cruz Pachacuti 1995:92 [1613: fol. 33v.]; Guaman Poma 1987:254 [1615: fol. 262 [264]]; Guaman Poma 1987: [1615: fol. 265 [267]]; Guaman Poma 1987:406407 [1615: fol. 398[400]]; Guaman Poma 1987:390-391 [1615: fol. 384[386]]; Guaman Poma 1987:392 [1615: fol. 385[387]]; Guaman Poma 1987:452 [1615: fol. 445[447]]; Cobo 2003:202 [1653]).

- Yllapa Usno (Albornoz 1990: 265 [1584: fol. 48r.]; Albornoz 1990: 265 [1584: fol. 48r.]; Albornoz 1990: 266 [1584: fol. 48v.]; Al- 
bornoz 1990: 268 [1584: fol. 49v.]; Albornoz 1990: 274 [1584: fol. 54r.]; Albornoz 1990: 274 [1584: fol. 54v.]; Albornoz 1990: 275 [1584: fol. 55r.]; Albornoz 1990: 275 [1584: fol. 55r.]; Albornoz 1990: 276 [1584: fol. 55r.-55v.]; Albornoz 1990: 276 [1584: fol. 55v.]; Albornoz 1990: 276 [1584: fol. 55v.]).

- Yllapa Usnu (Albornoz 1990: 267 [1584: fol. 49r.]; Albornoz 1990: 267 [1584: fol. 49v.]).

- Yllapa Ozno (Albornoz 1990: 267 [1584: fol. 49r.]).

- Yllapob Oznos (Ochuylla poboznos) (Albornoz 1990: 275 [1584: fol. 54v.]).

- Yllapa Osno (Albornoz 1990: 267 [1584: fol. 49r.]).

- Oznos (Albornoz 1990: 287 [1584: fol. 63r.]).

- Husnu (Bertonio 2006:77 [1612]) (Noboa 2003:429 [1657: fol. 63v.]).

- Capac Usno (Santa Cruz Pachacuti 1995:92 [1613: fol. 32r.]) para referirse al Usno de Vilcashuaman.

- Usmo (Murúa 2001: 103 [1615: Libro I, Capitulo 31]).

- Chuquipillaca (Murúa 2001: 103 [1615: Libro I, Capitulo 31]).

- Oznuro (Cobo 2003:213 [1653]).

\section{Contexto general del Ushnu}

\section{Sobre la mención de lugares o provincias donde se encontraban los Ushnu}

Las fuentes mencionan lugares específicos con nombre propio donde se identifico había un Ushnu, y estos lugares fueron:

- Cuzco, donde se encontraba el Ushnu más famoso (Betanzos 1987:52 [1551]; Betanzos 1987:53 [1551]; Cieza de León 1986:69 [1553: fol.30v.]; Las Casas 1892: 132 [1561]; Anónimo 1906:151 [Ca. 1565]; Anónimo 1906:158 [Ca. 1565]; Guaman Poma 1987:406-407 [1615: fol. 398[400]]; Murúa 2001: 103 [1615: Libro I, Capitulo 31]).
- Vilcashuaman en Ayacucho, refiriéndose a Bilcas (Albornoz 1967: 24 [1582]; Santa Cruz Pachacuti 1995:64 [1613: fol. 21r.]), o al Capac Usno de Vilcas (Santa Cruz Pachacuti 1995:92 [1613: fol. 32r.]) y Bilcas Guaman (Guaman Poma 1987:452 [1615: fol. 445[447]]).

- Huánuco Pampa refiriéndose como Guanaco el viejo (Albornoz 1967: 24 [1582]).

- Tiahuanaco y Pucara en el altiplano sureño (Albornoz 1967: 24 [1582]).

- Soras como un curacazgo en Ayacucho (Albornoz 1990: 264 [1584: fol. 47v.]).

- Lucanas como Anan Lucanas (Albornoz 1990: 287 [1584: fol. 63r.]).

- Cajamarca (Guaman Poma 1987:390391 [1615: fol. 384[386]]; Guaman Poma 1987:392 [1615: fol. 385[387]]).

- Tomebamba en Ecuador (Murúa 2001: 103 [1615: Libro I, Capitulo 31]).

- Guamañin o Guamani en Ayacucho (Santa Cruz Pachacuti 1995:64 [1613: fol. 21r.]).

- Titicaca mencionado como Tichicasa (Sancho de la Hoz 1968:331-332 [1534: Capitulo 18]), ó Titicaca (Ramos Gavilán 1988: 116 [1621:lib.1, cap. 17]; Cobo 1956:193 [1653: Libro 13, Capitulo 18]).

- Tauya en Cajatambo (Noboa 2003:351 [1657: fol. 19v.]).

- Carhuarazo donde se ofrendo una Capaccocha, posiblemente al pie del principal volcán-nevado en Ayacucho (Albornoz 1990: 276 [1584: fol. 55v.]).

Sobre los personajes asociados al Ushnu y a los rituales de libación

Los personajes que principalmente accedían o usaban los Ushnu en los rituales de libación, o que interactuaban en torno a los Ushnu, se menciona que eran:

- El Sapa Inka o gobernante supremo del Tawantinsuyu principalmente (Betanzos 1987:185 [1551]; Molina 1968: 316 [1553]; Hernández Príncipe 2003:743 [1621]; Molina 2008:160 [1575: fol. 14r.]; Lizárraga 
1916: 198-199 [1591: Cap. 80]; Garcilazo de la Vega 1991:372 [1609:lib.6, Cap. 21]), ya que primordialmente era el Sapa Inka el que se encargaba de brindar con las deidades mas importantes, especialmente con el Sol. Por tanto se percibe al Ushnu como el espacio social más importante para el posicionamiento y la ubicación del gobernante Inka en los rituales, sobre todo los de libación. Por lo que algunos autores mencionan al Ynga situado en su asiento que es el Ushnu (Titu Cusi Yupanqui 1992:7 [1570: fol. 4r-4v]; Guaman Poma 1987:452 [1615: fol. 445[447]]). Y asimismo el Ushnu en las reuniones militares, era el lugar de ubicación de todos los gobernantes o "reyes" Inkas según Pedro Cieza de León (Cieza de León 1986:69 [1553: fol.30v.]), o principalmente donde se posicionaba el Inka mencionado como el "señor" (Cieza de León 1995:252 [1553: fol.115v.]).

- Ynga Yupangue más conocido como Pachacutec, como el que dio la orden de realizar sacrificios y libaciones (Betanzos 1987:51 [1551]; Betanzos 1987:52 [1551]), asimismo es el que dio servicios de oro y plata para estos rituales (Sarmiento de Gamboa 1943:187 [1572: Cap. 36]), y que ordeno que se realice estos rituales en el Coricancha del Cuzco y en todos los Ushnu de todos los Wamani o provincias Inka (Guaman Poma 1987: [1615: fol. 265 [267]]).

- Atahualpa Inga como el personaje que se situaba encima del Ushnu de Cajamarca, y que según el imaginario de Guaman Poma ahí se dio la primera entrevista con Francisco Pizarro y el Padre Valverde. (Guaman Poma 1987:390-391 [1615: fol. 384[386]]; Guaman Poma 1987:392 [1615: fol. 385[387]]).

- Los Kurakas o autoridades importantes denominadas como "Señores" a quien el Inka hacia subir junto a él, y se menciona a "tres señores" (Molina 1968: 316 [1553]), o a "senores principales" que eran autoridades del más alto rango de las localidades, que posteriormente en un caso, los españoles hicieron subir al Ushnu de Vilcashuaman, en especial al "más viejo y principal" de la jurisdicción o provincia de los Lucanas, Andamarcas y Soras que era Don Alonso Naccha Uarcaya del pueblo de San Pedro de Queca (Guaman Poma 1987:452 [1615: fol. 445[447]]).

- Los oficiantes, denominados según las fuentes como los "sacerdotes", encargados de quemar las ofrendas y dar de beber a las deidades (Las Casas 1892: 58 [1561]), que principalmente también brindaban o "los sacerdotes que bebian unos con otros" (Molina 2008:160 [1575: fol. 14r.]), o conocidos también como los "ministros" de los ídolos (Noboa 2003:335 [1657: fol. 10]).

- La Coya esposa-hermana del Sapa Inka acompañada de las Pallas, quienes eran personajes femeninos emparentadas con el Inka, encargadas de traer la bebida o "chicha" para los rituales de libación (Hernández Príncipe 2003:743 [1621]).

- Los Yllapa, que eran los "cuerpos embalsamados" de los Inkas y principales (Albornoz 1967: 19 [1582]), a quienes se les daba de beber en unos recipientes especiales (Guaman Poma 1987:284-285 [1615: fol. 287288[289-290]]) y se decía que estos "cuerpos embalsamados" bebían (Molina 2008:160 [1575: fol. 14r.]), y estos "Ingas embalsamados" en las fiestas se situaban junto al Sapa Inka y las principales deidades (Hernández Príncipe 2003:743 [1621]). (Ver Fig. 2 )

- Los Mallqui que eran los cuerpos de difuntos importantes, con quienes se brindaba y a quienes se daba de beber en los Ushnu (Noboa 2003:429 [1657: fol. 63v.]; Noboa 2003:335 [1657: fol. 10]), tal es el caso de dos Mallqui importantes del pueblo de San Pedro de Hacas como son los de "Yanayacallua Libia y Yanayacolca Libia" (Noboa 2003:351 [1657: fol. 19v.]), además que generalmente situaban a los "muertos" junto a sus Ushnu para que pudieran brindar con otros "muertos" y también con los vivos (Pizarro 1968:495 [1571]).

- Los "Abuelos" o personas difuntas también, 


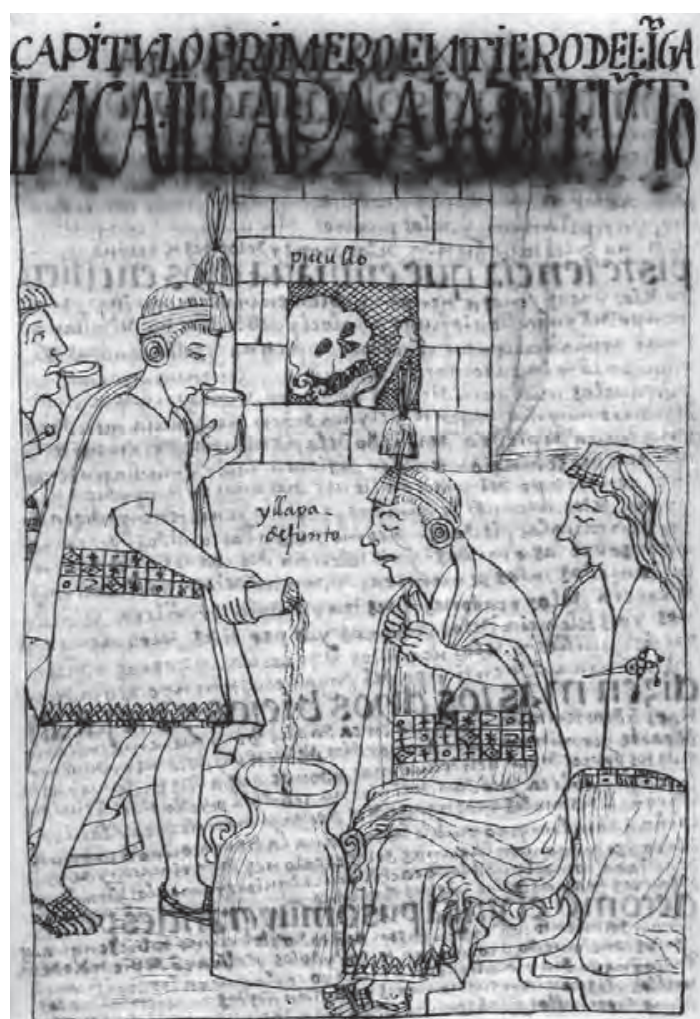

Figura 2: Yllapa o Inka difunto bebiendo en una gran vasija (Guaman Poma 1987 [1615]).

enterradas en las iglesias, pero que se les daba de beber simbólicamente en las plazas (Noboa 2003:335 [1657: fol. 10]).

- Las personas del linaje de los Inkas, en este caso se menciona que en el lugar donde se construyo el Ushnu del Cuzco, previamente se realizaron ofrendas de todas las personas principales del Cuzco desde los descendientes de Manco Capac (Betanzos 1987:53 [1551]).

- La población general, es mencionada también indicando que como personas "del común”, al no poder acceder a las exclusivas casas de las deidades podían adorarlas fuera de ellas en los Ushnu de las plazas (Betanzos 1987:52 [1551]), o que todos los "de la comarca" podían realizar sus sacrificios en la plaza (Anónimo 1906:158 [Ca. 1565]).

- Francisco de Toledo, cuarto virrey del Perú, se menciona también que fue un personaje que uso el Ushnu a manera de legitimar su poder en las provincias y que se subió al Ushnu de Vilcashuaman junto con los "señores principales" de esa provincia (Guaman Poma 1987:452 [1615: fol. 445[447]]).

\section{Deidades asociadas al Ushnu}

En los documentos revisados se menciona que las principales deidades que tenían los Ushnu para sus rituales eran:

- El Sol principalmente tal como lo percibieron los españoles, así lo mencionan casi todas las fuentes de forma recurrente, por lo que se puede indicar tentativamente que el Ushnu era de carácter solar (Ruiz de Arce 1968:432 [1545]; Betanzos 1987:51 [1551]; Betanzos 1987:52 [1551]; Las Casas 1892: 58 [1561]; Las Casas 1892: 132 [1561]; Anónimo 1906:151 [Ca. 1565]; Anónimo 1906:158 [Ca. 1565]; Sarmiento de Gamboa 1943:187 [1572: Cap. 36]; Molina 2008:160 [1575: fol. 14r.]; Albornoz 1967: 24 [1582]; Albornoz 1967: 26 [1582]; Lizárraga 1916: 198-199 [1591: Cap. 80]; Garcilazo de la Vega 1991:372 [1609:lib.6, Cap. 21]; Guaman Poma 1987:254 [1615: fol. 262[264]]; Murúa 2001: 103 [1615: Libro I, Capitulo 31]; Hernández Príncipe 2003:743 [1621]).

- El dios Wiracocha, mencionado como el "Hacedor" (Molina 2008:160 [1575: fol. 14r.]), ó "Viracochan" (Santa Cruz Pachacuti 1995:92 [1613: fol. 32r.]).

- Las deidades del Trueno, Rayo y Relámpago (Molina 2008:160 [1575: fol. 14r.]; Hernández Príncipe 2003:743 [1621]; Albornoz 1990: 287 [1584: fol. 63r.]).

- Los Yllapa, indicados como los difuntos embalsamados de las autoridades principales considerados como sagrados (Albornoz 1990: 265 [1584: fol. 48r.]).

- Llocllahuancupa, una deidad de Huarochirí que fue hijo del dios Pachacamac (Taylor 2003:101-102 [1608]; Taylor 2003: 92-93 [1608]).

- Los Mallquis considerados como númenes también, ya se mencionó el caso de Yana- 
yacallua Libia y Yanayacolca Libia (Noboa 2003:351 [1657: fol. 19v.]).

- Las Huacas en general considerados como cosas o lugares sagrados (Noboa 2003:335 [1657: fol. 10]; Guaman Poma 1987:254 [1615: fol. 262 [264]]; Guaman Poma 1987: [1615: fol. 265 [267]]), o deidades indígenas considerado como "Demonios" (Hernández Príncipe 2003:743 [1621]).

\section{Marco temporal de uso del Ushnu}

Las ocasiones en que se realizó importantes rituales de libación y se habrían usado los Ushnu, habrían sido:

- Durante los sacrificios de cada día (Las Casas 1892: 58 [1561]), posiblemente "luego que rayaba el sol por la mañana" (Noboa 2003:429 [1657: fol. 63v.]).

- Principalmente en las "fiestas" (Molina 2008:160 [1575: fol. 14r.]; Santa Cruz Pachacuti 1995:92 [1613: fol. 31v.-31r.]; Noboa 2003:331 [1657: fol.6]), fiestas de las huacas cuando se les daba de beber (Villagomez 1919:163 [1649: Capitulo 45]), fiestas de los Mallquis o Abuelos (Noboa 2003:335 [1657: fol. 10]).

- Fiestas de medio año o mencionadas como "fiestas de entre año" (Hernández Príncipe 2003:745 [1621]).

- En la fiesta de los santos, como San Pedro y en la fiesta del Corpus Christi (Noboa 2003:335 [1657: fol. 10]).

- En los rituales del mes de Setiembre (Anónimo 1906:158 [Ca. 1565]).

- En los rituales antes de empezar hacer las chacras y cosechas (Noboa 2003:351 [1657: fol. 19v.]).

- Al principio de las primeras aguas o primeras lluvias (Noboa 2003:429 [1657: fol. 63v.]).

\section{Sobre qué tipo de lugar eran considerados los Ushnu}

Los espacios de libación y los Ushnu generalmente estaban asociados al culto de los ancestros, por lo tanto eran reverenciados como lugares sagra- dos y se menciona que eran considerados como:

- Principalmente como Huaca o lugares sagrados (Albornoz 1967: 24 [1582]; Albornoz 1967: 19 [1582]; Albornoz 1990: 264 [1584: fol. 47v.]; Murúa 2001: 103 [1615: Libro I, Capitulo 31]; Cobo 2003:202 [1653]).

- Altares de las Huacas o de las deidades en este caso (Bertonio 2006:77 [1612]).

- Adoratorios (Albornoz 1990: 264 [1584: fol. 47v.]), o templos naturales (Valera 1945:12 [1585]).

- Lugares donde se realizaba el sacrificio de la Capaccocha (Albornoz 1990: 276 [1584: fol. 55v.]; Guaman Poma 1987:254 [1615: fol. 262[264]]), como la Capaccocha del Carhuarazo (Albornoz 1990: 276 [1584: fol. 55v.]).

- Santuarios dedicados a las deidades, como en la región de Huarochirí, en los que en uno de ellos se encontraba una olla en el interior para colocar keros con chicha para las deidades (Taylor 2003:101-102 [1608]).

\section{El Ushnu como Instalación Ritual}

\section{Sobre la ubicación espacial del Ushnu}

Según las fuentes, los lugares de libación con las deidades y la ubicación del Ushnu se encontraban en ciertos espacios específicos tales como:

- La Plaza, era el lugar donde recurrentemente se menciona estaba la ubicación del Ushnu, sobre todo en la plaza del Cuzco (Betanzos 1987:185 [1551]; Betanzos 1987:52 [1551]; Betanzos 1987:53 [1551]; Cieza de León 1986:69 [1553: fol.30v.]; Albornoz 1967: 26 [1582]; Murúa 2001: 103 [1615: Libro I, Capitulo 31]; Hernández Príncipe 2003:743 [1621]), o como algunos autores indican que se encontraba en la plaza grande real (Molina 1968: 316 [1553]), la plaza mayor (Garcilazo de la Vega 1991:372 [1609:lib.6, Cap. 21]), la Plaza del Haucaypata (Santa Cruz Pachacuti 1995:92 [1613: fol. 32r.]), o la otra plaza importante del Cuzco que era la plaza de Hurin Haucaypata (Cobo 2003:202 [1653]). Asimismo algunas fuentes gene- 
ralizan que se podía ubicar estos lugares de libación en las plazas (Albornoz 1967: 24 [1582]; Noboa 2003:331 [1657: fol.6]), pero específicamente a la "mitad" de ellas (Cieza de León 1986:91 [1553: fol.38v.]; Cieza de León 1995:252 [1553: fol.115v.]; Pizarro 1968:495 [1571]; Pizarro 1968:496 [1571]), "en medio" de la plaza o de la gran plaza para referirse a la plaza más importante(Cieza de León 1995:252 [1553: fol.115v.]; Anónimo 1906:151 [Ca. 1565]; Anónimo 1906:158 [Ca. 1565]; Titu Cusi Yupanqui 1992:7 [1570: fol. 4r-4v]; Molina 2008:155 [1575: fol. 11v.]), que generalmente eran "en medio" las plazas públicas (Guaman Poma 1987:392 [1615: fol. 385[387]]), donde la plaza era el lugar donde los pueblos se juntaban a comer y beber (Noboa 2003:335 [1657: fol. 10]).

- En el inicio de los ceques y casi al centro del Cuzco, tal como se menciona que el Usno era la primera huaca del quinto ceque del Antisuyu (Cobo 2003:202 [1653]), y el Oznuro era la primera guaca del decimocuarto ceque del Cuntisuyu (Cobo 2003:213 [1653]).

- Los "pueblos" como centros de concentración de poblaciones eran espacios que albergaban un Ushnu (Molina 1968: 316 [1553]; Albornoz 1967: 24 [1582]), sea de la misma manera en cada "ciudad" si se quiere referir de este modo (Betanzos 1987:51 [1551]), Juan de Betanzos indica que el Ushnu de Cuzco se ubicaba donde los españoles pusieron posteriormente el "royo" (Betanzos 1987:52 [1551]), o rollo español que era una estructura cilíndrica o columnaria sobre un pedestal donde se exponía y castigaba a los reos en la época de la colonia.

- En cada "guamani" o provincia inka (Guaman Poma 1987: [1615: fol. 265 [267]]), cada cierto tramo o "en cada guamanin de treinta leguas" (Santa Cruz Pachacuti 1995:92 [1613: fol. 33v.]), que era sabido que en cada provincia había un lugar como "tierra señalado para sacrificios" (Guaman Poma 1987:254 [1615: fol. 262[264]]), en todo el Tawantinsuyu o dicho como "en todo este reino" (Guaman Poma 1987:254 [1615: fol. 262[264]]).

- En los caminos reales o vías del Qhapaq Nan (Albornoz 1967: 24 [1582]).

- En cada quebrada (Santa Cruz Pachacuti 1995:22 [1613: fol. 9v.]; Santa Cruz Pachacuti 1995:92 [1613: fol. 33v.]).

- En las punas o lugares de gran altura (Bertonio 2006:77 [1612]).

- En el patio del Coricancha o de la casa del Sol, se encontraba un Ushnu muy especial (Las Casas 1892: 132 [1561]).

- En los campos de cultivo chacras o "chacaras" (Hernández Príncipe 2003:745 [1621]; Cobo 2003:213 [1653]; Noboa 2003:351 [1657: fol. 19v.]), o en medio de ellas (Noboa 2003:429 [1657: fol. 63v.]).

- En pequeños espacios cercados o "corralito" (Noboa 2003:429 [1657: fol. 63v.]).

- Al pie o delante de rocas importantes, como "delante de la peña" que rendían culto en la Isla del Sol en el lago Titicaca (Ramos Gavilán 1988: 116 [1621:lib.1, cap. 17]; Cobo 1956:193 [1653: Libro 13, Capitulo 18]), al pie de una cruz situada en la misma peña en el Titicaca (Cobo 1956:193 [1653: Libro 13, Capitulo 18]).

- Fuera de las iglesias o en la parte externa de ellas, debido a que los ancestros objeto de culto estaban enterrados en ellas y las libaciones tenían que realizarse afuera (Noboa 2003:335 [1657: fol. 10]).

\section{Sobre el tipo de construcción, descripciones y morfología del Ushnu}

Según las fuentes la apariencia del Ushnu o de las construcciones donde se encontraba era como:

- Una construcción muy bien hecha con piedra trabajada o de "cantería" (Betanzos 1987:53 [1551]), que era una "cantería muy hermosa" (Albornoz 1967: 24 [1582]; Garcilazo de la Vega 1991:372 [1609:lib.6, Cap. 21]).

- Un “Castillejo” (Betanzos 1987:185 [1551]), o con forma de una "fortaleza" (Titu Cusi 
Yupanqui 1992:7 [1570: fol. 4r-4v]), o "torres" mencionado como "a hechura de torres" (Albornoz 1967: 24 [1582]).

- Un "edificio" (Murúa 2001: 103 [1615: Libro I, Capitulo 31]), dando a entender también que para los Ushnu "a todos les tenían hechos edificios" (Albornoz 1967: 24 [1582]).

- Un "teatro" (Cieza de León 1986:91 [1553: fol.38v.]; Cieza de León 1995:252 [1553: fol.115v.]; Anónimo 1906:158 [Ca. 1565]), entendiéndose como un lugar que servía de escenario para actos públicos. (Ver Fig. 3)

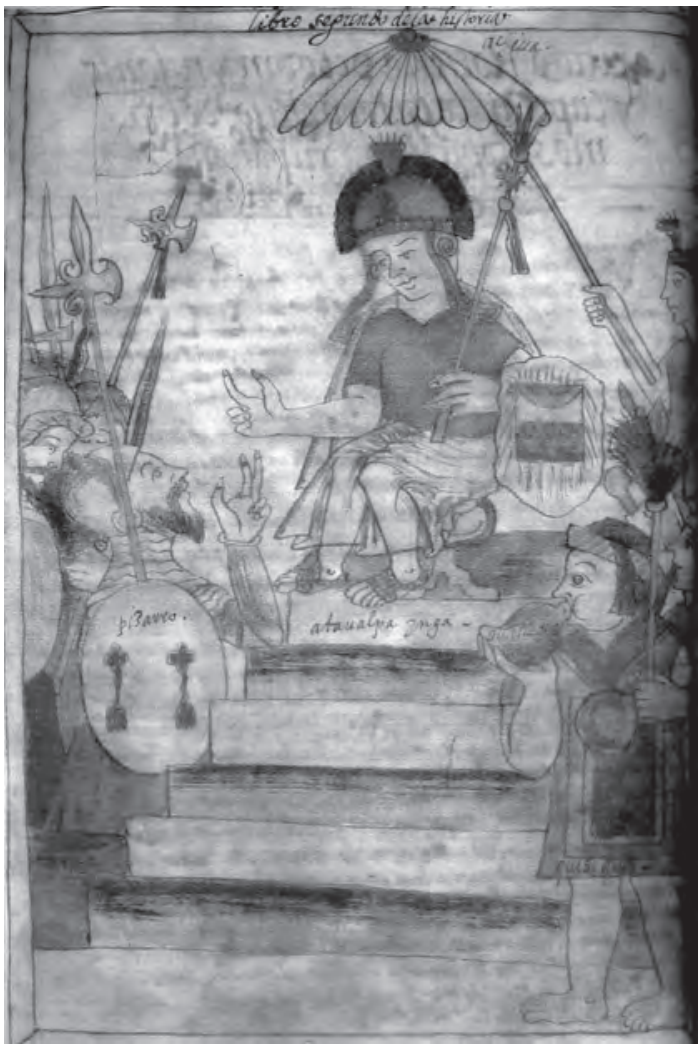

Figura 3: Inka Atahualpa en un Ushnu según Martín de Murúa (2004 [1590]).

- Una plataforma o "terraplen" (Molina 1968: 316 [1553]), describiéndose también como un "cuadro alto" (Molina 1968: 316 [1553]).

- Un "altar" o con forma de un lugar elevado destinado a realizar sacrificios y cultos (San- to Thomas 2006:474 [1560:f9v.]; Santo Thomas 2006:157 [1560:f9v.]; Santo Thomas 2006:599 [1560:f157v.]; Sarmiento de Gamboa 1943:187 [1572: Cap. 36]; Bertonio 2006:77 [1612]; Cobo 1956:193 [1653: Libro 13, Capitulo 18]). Algunos autores recientes como Frank Salomon (Salomon 2006: 114) y Gabriel Ramón (2008, com. per.), mencionan que la peana española podía ser el remplazo del usnu prehispánico por su forma piramidal debido a que una peana o peaña era a manera de tarima o base que servía para colocar algún objeto sagrado, generalmente estas peanas estaban ubicadas al pie de los altares o arrimados a ellos.

- Un "Ara" o piedra para realizar cultos (Santo Thomas 2006:157 [1560:f9v.]; Sarmiento de Gamboa 1943:187 [1572: Cap. 36]), que en algunos casos viene a ser como un "altar de piedra" (Valera 1945:12 [1585]).

- Un tribunal entendido como un pulpito o plataforma elevada ó "tribunal de juez" (Gonzales Holguín 1989:358 [1608]).

- Un "mojón” o "mojones" (Gonzales Holguín 1989:358 [1608]; Santa Cruz Pachacuti 1995:64 [1613: fol. 21r.]), como una construcción a manera de hito o señal.

Las descripciones indican que el Ushnu de Cuzco, tenía la forma de:

- Un pan de azúcar ó "a la hechura de un pan de azúcar puntiaguda para arriba" (Betanzos 1987:52 [1551]; Cieza de León 1986:69 [1553: fol.30v.]), o a "manera de teta" (Pizarro 1968:496 [1571]), pero se entiende como de forma cónica o convexa, con la punta o prominencia hacia arriba.

- De forma redonda (Betanzos 1987:53 [1551]), o con la "figura de un bolo" (Albornoz 1967: 24 [1582]).

Sobre el tamaño del Ushnu de Cuzco, se indica que era:

- Grande o "una piedra grande" (Cieza de León 1986:69 [1553: fol.30v.]).

- "De un estado de alto" (Anónimo 1906:151 [Ca. 1565]), donde un estado como medi- 
da española equivale a $1.6718 \mathrm{~m}$. (Agurto 1987: 277).

- "De altor de medio estado" (Betanzos 1987:53 [1551]), o equivalente a $0.8369 \mathrm{~m}$.

- Para otros lugares de libación se menciona que eran "del tamaño de una piedra de molino" (Cobo 1956:193 [1653: Libro 13, Capitulo 18]).

Otras descripciones indican que los Ushnu eran a manera de:

- "Sepulturas donde se vierten brebajes" (Cieza de León 1995:277 [1553: fol.126v.]).

- "templos naturales sin hacer edificio alguno" (Valera 1945:12 [1585]).

- Recintos, tales como una "cancha" o recinto cercado (Noboa 2003:351 [1657: fol. 19v.]), o un "corralito pequeño" (Noboa 2003:351 [1657: fol. 19v.]; Noboa 2003:429 [1657: fol. 63v.]).

\section{Sobre el material de construcción del Ushnu}

Generalmente el Ushnu estaba compuesto de material lítico según las fuentes, tal como se indica en detalle a continuación:

- Erauna "piedra" (SanchodelaHoz 1968:331332 [1534: Capitulo 18]; Betanzos 1987:52 [1551]; Betanzos 1987:53 [1551]; Betanzos 1987:53 [1551]; Cobo 2003:202 [1653]; Cobo 2003:213 [1653])

- Una "piedra no pequeña" (Cieza de León 1995:252 [1553: fol.115v.]).

- Una "piedra en medio de la plaza" del Cuzco (Betanzos 1987:53 [1551]).

- Una "piedra que significaba el Sol" (Betanzos 1987:53 [1551]).

- Una piedra también conocida como la "piedra de la guerra" (Cieza de León 1986:69 [1553: fol.30v.]).

- Una "piedra redonda" (Pizarro 1968:495 [1571]), "piedra redonda a manera de teta" (Pizarro 1968:496 [1571]).

- Una "piedra redonda a la traza de una vasija" (Ramos Gavilán 1988: 116 [1621:lib.1, cap. 17]), o una piedra redonda "a modo de vacía" (Cobo 1956:193 [1653: Libro 13, Capitulo 18]), dando a entender que se trataba de un receptáculo de piedra.

- La piedra era el material escogido del que estaban hecho los receptáculos que tenían los Ushnu, ya sea como una "muy linda pileta de piedra” (Las Casas 1892: 58 [1561]), o una "pila de piedra" (Molina 2008:160 [1575: fol. 14r.]; Lizárraga 1916: 198-199 [1591: Cap. 80]), también como una "bien hecha pila de piedra” (Las Casas 1892: 132 [1561]) ó "pilar de piedra" (Anónimo 1906:158 [Ca. 1565]).

- La piedra era trabajada, mencionándose que los Ushnu eran de "piedra labrada" (Las Casas 1892: 132 [1561]), ó tenían las "piedras labradas" (Bertonio 2006:77 [1612]), que tenían la piedra "muy labrada" (Anónimo 1906:151 [Ca. 1565]), "bien acabada" (Ramos Gavilán 1988: 116 [1621:lib.1, cap. 17]) ó "admirablemente labrada" (Cobo 1956:193 [1653: Libro 13, Capitulo 18]).

- También podía decirse que eran "piedras llevadas y puestas como estrado" (Santa Cruz Pachacuti 1995:22 [1613: fol. 9v.]).

- O se trataba de una "piedra hincada" ó "piedra grande hincada" (Gonzales Holguín 1989:358 [1608]).

- Asimismo, se indica que esta construcción con forma de bolo "estaba hecha de muchas diferencias de piedras" (Albornoz 1967: 24 [1582]), por lo que el Inka "hacia llevar piedras" para su confección (Santa Cruz Pachacuti 1995:22 [1613: fol. 9v.]). Sin embargo, Juan de Betanzos da una descripción más específica, en la que indica que la "pileta" hecha de piedra estaba también "llena de piedras” (Betanzos 1987:185 [1551]).

Otro material del que se menciona estaban compuestos los Ushnu y los lugares de libación de los Inkas era el oro, tal como se detalla a continuación:

- De oro, según las distintas formas (Sancho de la Hoz 1968:331-332 [1534: Capitulo 18]; Ruiz de Arce 1968:432 [1545]; Betanzos 1987:52 [1551]; Cieza de León 1986:91 
[1553: fol.38v.]; Molina 2008:155 [1575: fol. 11v.]; Albornoz 1967: 26 [1582]).

- Tenía un "dúo de oro" (Hernández Príncipe 2003:743 [1621]).

- Un de "tinajón oro" (Garcilazo de la Vega 1991:372 [1609:lib.6, Cap. 21]).

- Estaba "forrada con una faja de oro" (Betanzos 1987:52 [1551]), o "era una pila de piedra forrada de oro" (Molina 2008:160 [1575: fol. 14r.]), "engastonada y llena de oro" (Cieza de León 1986:69 [1553: fol.30v.]).

- Los receptáculos para las libaciones eran unos "cangilones" o "verquis" de oro, plata y barro (Pizarro 1968:495 [1571]).

- En el Coricancha, el receptáculo de libaciones tenía un "cobertor" (Ruiz de Arce 1968:432 [1545]), que según una fuente era una "lamina de oro que cubría la boca de la pila" (Lizárraga 1916: 198-199 [1591: Cap. 80]).

- Asimismo, el menaje que se usaba en los rituales de libación era de oro y de plata (Albornoz 1967: 24 [1582]).

\section{Sobre las instalaciones en el Ushnu con propósitos particulares}

Los documentos muestran que los rituales de libación no eran tan sencillos, sino que requerían de todo un mecanismo, mediante el cual se entendiera que las deidades y las momias de los ancestros estaban bebiendo lo que se les ofrecía. Por lo cual los documentos al describir el Ushnu del Cuzco, de acuerdo al entender de los testigos españoles, detallan que para las libaciones había recipientes específicos con sus respectivos drenajes, indicando que para la recepción de ofrendas liquidas había:

- Una "fuente" (Ruiz de Arce 1968:432 [1545]).

- Una "alberca alrededor de la ídolo" que era una "piedra redonda" (Pizarro 1968:495 [1571]).

- Una "pileta" (Betanzos 1987:185 [1551]; Las Casas 1892: 58 [1561]), como se dijo anteriormente se indica que la "pileta" asimismo estaba "llena de piedras" (Betanzos 1987:185 [1551]).
- Una "pila" (Betanzos 1987:53 [1551]; Las Casas 1892: 132 [1561]; Sarmiento de Gamboa 1943:187 [1572: Cap. 36]), o un receptáculo "a manera de pila" (Cieza de León 1995:252 [1553: fol.115v.]; Molina 2008:155 [1575: fol. 11v.]; Molina 2008:160 [1575: fol. 14r.]), que era una "pila grande" (Lizárraga 1916: 198-199 [1591: Cap. 80]), o un "pilon" (Pizarro 1968:496 [1571]), del tamaño de una "pila de altor de medio estado" (Betanzos 1987:53 [1551]), con forma de "pila redonda" (Betanzos 1987:53 [1551]).

- La pila, se describe que también era de forma "ochavada" es decir con ocho lados (Lizárraga 1916: 198-199 [1591: Cap. 80]) y el receptáculo se describe que "de hueco debe tener, por cualquiera parte que la midan, mas de vara y media, y de fondo mas de vara y cuarta" (Lizárraga 1916: 198-199 [1591: Cap. 80]), es decir que, siendo una vara española equivalente a $0.8359 \mathrm{~m}$, entonces la pila de diámetro tenía más de $1.25385 \mathrm{~m}$ y de fondo más de 1.044875 m. (Ver Fig. 4)

- Un "agujero" que tenia la pila (Molina 2008:160 [1575: fol. 14r]]) por donde evacuaba las ofrendas. Se menciona también que la piedra de libaciones del la roca sagrada en Titicaca tenía su "orificio" (Cobo 1956:193 [1653: Libro 13, Capitulo 18]).

- Un "albañar" o conducto de salida, al que llegaban los líquidos para drenarlos (Molina 2008:160 [1575: fol. 14r.]).

- Un "arcadus" a la manera de un caño o conducto, también es descrito para un Usnu de Aija en Ocros (Hernández Príncipe 2003:745 [1621]).

- Un "sumidero debajo de la pileta" por "donde se consumía" las ofrendas liquidas (Las Casas 1892: 58 [1561]), que donde se echaba los líquidos era en una "pila que tenía un sumidero" (Sarmiento de Gamboa 1943:187 [1572: Cap. 36]).

- Un "tinajon del que salia un caño" también se describe para indicar el receptáculo mas su drenaje (Garcilazo de la Vega 1991:372 [1609:lib.6, Cap. 21]). 


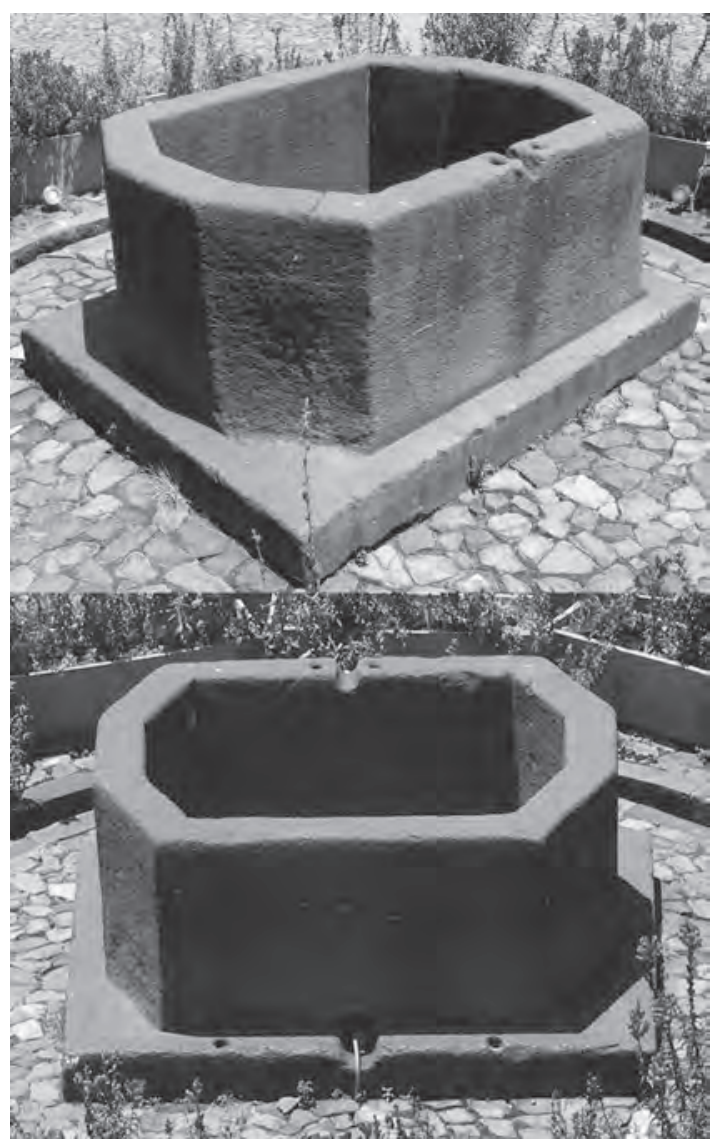

Figura 4: Pila de piedra de forma ochavada en el patio del Qoricancha en Cuzco.

- Un "caño de muy hermosa cantería" (Garcilazo de la Vega 1991:372 [1609:lib.6, Cap. 21]), o "caños debajo de la tierra" (Pizarro 1968:495 [1571]) para indicar los canales o drenajes por los cuales salían las ofrendas liquidas de las pilas o receptáculos, de esta manera "el caño que iba por debajo de la tierra" (Molina 2008:160 [1575: fol. 14r.]) llevaba el producto de las libaciones "hasta las casas del sol, trueno y hacedor de donde bebian los sacerdotes con las momias" (Molina 2008:160 [1575: fol. 14r.]).

- Hubo también un "hoyo" debajo del Ushnu en Cuzco (Betanzos 1987:53 [1551]), donde se enterraron ofrendas.

- Un "pilar" (Anónimo 1906:151 [Ca. 1565]; Albornoz 1967: 26 [1582]) entendiéndose como una columna que servía para observaciones astronómicas.

Los monumentos y construcciones asociados al Ushnu

El Ushnu en Cuzco, a pesar de ser una estructura al centro de la plaza principal en un espacio público abierto, estaba vinculada de una forma muy estrecha a otra construcción o conjunto de estructuras, y en este caso era a los lugares donde residían las deidades, como el Coricancha, donde también se daban rituales de libación de formas más privadas, por lo que los documentos indican que el Ushnu estaba asociado con:

- La "casa del Sol" (Sancho de la Hoz 1968:331. 332 [1534: Capitulo 18]; Betanzos 1987:51 [1551]; Betanzos 1987:53 [1551]; Las Casas 1892: 132 [1561]; Molina 2008:160 [1575: fol. 14r.]; Guaman Poma 1987: [1615: fol. 265 [267]]), especificándose que a partir del Ushnu un caño "iba hasta la casa del sol" (Garcilazo de la Vega 1991:372 [1609:lib.6, Cap. 21]), mediante el cual ambos se encontraban conectados.

- Los "templos principales del sol" (Las Casas 1892: 58 [1561]) donde se realizaban estos sacrificios.

- Las "casas del trueno" (Molina 2008:160 [1575: fol. 14r.]).

- Las "casas del hacedor" (Molina 2008:160 [1575: fol. 14r.]).

- El "Curicancha" (Guaman Poma 1987: [1615: fol. 265 [267]]).

Sobre los sistemas de acceso y desplazamiento al Ushnu

Las fuentes históricas mencionan que para acceder a las plataformas se observaban "gradas" (Cieza de León 1986:91 [1553: fol.38v.]; Guaman Poma 1987:392 [1615: fol. 385[387]]; Guaman Poma 1987:452 [1615: fol. 445[447]]), o una "escalera" (Molina 1968: 316 [1553]), en todo caso para desplazarse de la plaza hacia la cima de las plataformas debía hacerse mediante estas esca- 
leras o gradas, que debieron ser de construcción formal para el tránsito de los personajes asociados en las diversas ocasiones mencionadas.

\section{Sobre las divisiones y distribución de los participantes en los rituales de libación en torno al Ushnu}

Por lo que las fuentes mencionan, se entiende que los protagonistas de los principales rituales públicos se encontraban en un lugar "alto"
- Como un "asiento" (Betanzos 1987:185 [1551]; Titu Cusi Yupanqui 1992:7 [1570: fol. 4r-4v]; Ramos Gavilán 1988: 116 [1621:lib.1, cap. 17]), que era el "asiento del inga" (Guaman Poma 1987:390-391 [1615: fol. 384[386]]; Guaman Poma 1987:452 [1615: fol. 445[447]]), o una "silla" (Betanzos 1987:185 [1551]), ó “duo” (Hernández Príncipe 2003:743 [1621]) donde se "asienta" el Inka (Santa Cruz Pachacuti 1995:92 [1613: fol. 32r.]). (ver Fig. 5) (Betanzos 1987:185 [1551]), y que "en lo alto" se encontraban los objetos de culto, por lo que ponían "la figura del dios soberano hacedor" y que los oficiantes o "los sacerdotes estaban junto a él" (Cieza de León 1986:91 [1553: fol.38v.]), dando a entender que en estas actividades públicas, los personajes importantes generalmente se encontraban arriba, por lo que el lugar de libaciones era una plataforma ó un "cuadro alto" (Molina 1968: 316 [1553]) y que en la plaza, el Inka se posicionaba en un lugar "alto" (Titu Cusi Yupanqui 1992:7 [1570: fol. $4 r-4 v])$.

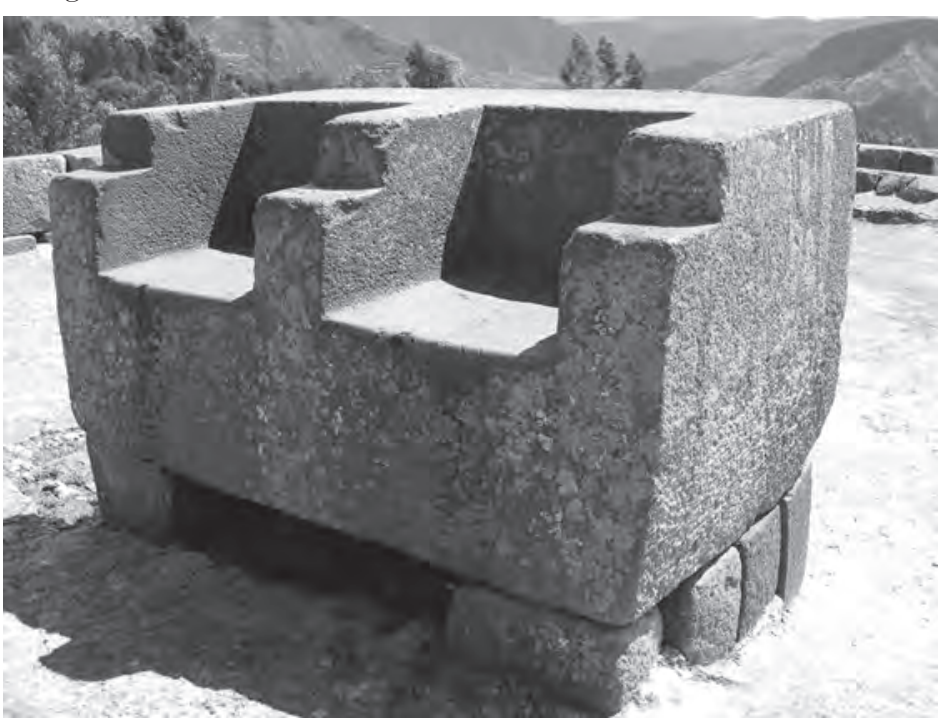

Figura 5: Trono o asiento de piedra del Ushnu de Vilcashuaman en Ayacucho.

- Como un "trono" (Guaman Poma 1987:390391 [1615: fol. 384[386]]), que específicamente era el "trono y asiento de los yngas" (Guaman Poma 1987: [1615: fol. 265 [267]]; Guaman Poma 1987:406-407 [1615: fol. 398[400]]; Guaman Poma 1987:392 [1615: fol. 385[387]]), o como un trono para las deidades, en este caso para el "viracocha" (Cieza de León 1986:91 [1553: fol.38v.]).

- Como el lugar de posición de personajes y autoridades importantes en los rituales de libación, por lo que estos personajes "se sentaban a beber" (Noboa 2003:331 [1657: fol.6]), y en el Ushnu se menciona que "sentavanse los señores a beber al sol" (Albornoz 1967: 24 [1582]). 
- Como un lugar por encima de la superficie de carácter importante para personajes protagónicos, por lo que se menciono también como un "tribunal de juez" (Gonzales Holguín 1989:358 [1608]), o un "estrado" (Santa Cruz Pachacuti 1995:22 [1613: fol. 9v.]).

\section{ActividAdes ReAlizADAS en los Ushnu}

\section{Acciones ceremoniales y religiosas}

De acuerdo a lo revisado, el Ushnu era un espacio eminentemente ceremonial y como se mencionó anteriormente, servía principalmente para la ejecución de rituales de libación como culto a las deidades y ancestros, por lo que las fuentes detallan que en este lugar se realizaban:

- La entrega de "ofrendas" (Sancho de la Hoz 1968:331-332 [1534: Capitulo 18]).

- Los "sacrificios" (Sancho de la Hoz 1968:331-332 [1534: Capitulo 18]; Ruiz de Arce 1968:432 [1545]; Betanzos 1987:185 [1551]; Betanzos 1987:51 [1551]; Betanzos 1987:53 [1551]; Betanzos 1987:53 [1551]; Cieza de León 1995:252 [1553: fol.115v.]; Santo Thomas 2006:474 [1560: f9v.]; Las Casas 1892: 58 [1561]; Molina 2008:155 [1575: fol. 11v.]; Albornoz 1967: 24 [1582]; Valera 1945:12 [1585]; Guaman Poma 1987:254 [1615: fol. 262 [264]]; Murúa 2001: 103 [1615: Libro I, Capitulo 31]; Villagomez 1919:163 [1649: Capitulo 45]; Noboa 2003:351 [1657: fol. 19v.]), que era un altar para sacrificar (Santo Thomas 2006:157 [1560:f9v.]; Santo Thomas 2006:599 [1560:f157v.]).

- El sacrificio de "animales y niños tiernos" (Cieza de León 1995:252 [1553: fol.115v.]).

- La degollación de animales como "cuyes" (Hernández Príncipe 2003:745 [1621]; Noboa 2003:429 [1657: fol. 63v.]).

- El "arpa" o sacrificio a personajes y deidades (Betanzos 1987:53 [151]).

- La acción de llenar o henchir de líquidos, tal como se menciona que "hinchian de cantidad de chicha" (Lizárraga 1916: 198-199 [1591: Cap. 80]).

- Las libaciones, al "echar" las ofrendas liquidas (Sancho de la Hoz 1968:331-332 [1534:
Capitulo 18]; Pizarro 1968:495 [1571]; Pizarro 1968:496 [1571]; Sarmiento de Gamboa 1943:187 [1572: Cap. 36]; Molina 2008:155 [1575: fol. 11v.]), se "echaba la chicha" (Ramos Gavilán 1988: 116 [1621: lib.1, cap. 17]; Cobo 1956:193 [1653: Libro 13, Capitulo 18]), el mismo Inka "echaba chicha" (Molina 2008:160 [1575: fol. 14r.]), o como se menciona también que "después que el inca bebía con el sol y echaba la chicha en el vaso grande de oro el sacerdote tomaba del vaso y lo echaba en la pila" (Molina 2008:160 [1575: fol. 14r.]), se "echaban muchos cantaros de este brebaje en una pila" (Sarmiento de Gamboa 1943:187 [1572: Cap. 36]), "echar en el fuego" (Sarmiento de Gamboa 1943:187 [1572: Cap. 36]), o se echaba las cenizas al "pilon" (Pizarro 1968:496 [1571]).

- La acción de vaciar líquidos (Betanzos 1987:185 [1551]), "volvían vacías las aquillas de chicha que tomaba el sol" (Hernández Príncipe 2003:743 [1621])

- La acción e consumir líquidos, al decirse que "se consumía" la ofrenda (Las Casas 1892: 58 [1561]), "la chicha se consumía" (Pizarro 1968:495 [1571]).

- La acción de "derramar" las ofrendas liquidas (Betanzos 1987:52 [1551]; Las Casas 1892: 58 [1561]; Noboa 2003:331 [1657: fol.6]), "derramar chicha a los mallquis, huacas y aguelos" (Noboa 2003:335 [1657: fol. 10]), "derramar la chicha delante de la huaca" (Villagomez 1919:157 [1649: Capitulo 44]), "derramando en señal que el idolo bebe" (Taylor 2000:83 [1609]), "derramaba el inca el vaso de la mano derecha que está dedicado al sol" (Garcilazo de la Vega 1991:372 [1609: lib.6, Cap. 21]).

- La acción de verter, indicándose que en el Ushnu se "vierten brebajes" (Cieza de León 1995:277 [1553: fol.126v.]; Sarmiento de Gamboa 1943:187 [1572: Cap. 36]), se "vertian mucha chicha para el sol" (Anónimo 1906:158 [Ca. 1565]).

- La acción de asperjar chicha a las deidades, pues se "asperjaban la chicha sobre las huacas" (Villagomez 1919:157 [1649: Capitulo 44]), se "asperjaba al sol" (Noboa 2003:429 [1657: fol. 63v.]). 
- La acción de beber definitivamente, por lo que el Ushnu era el lugar donde se "bebía" (Betanzos 1987:185 [1551]; Lizárraga 1916: 198-199 [1591: Cap. 80]), donde estaban "cuando bebían" (Molina 2008:155 [1575: fol. 11v.]), sobre todo se daba de beber al Sol como principal deidad, por lo que se indica que "el sol bajaba a beber" (Las Casas 1892: 132 [1561]), "daban de beber al el sol” (Ramos Gavilán 1988: 116 [1621:lib.1, cap. 17]), "bebian al sol" (Albornoz 1967: 26 [1582]), "bebían con el sol" (Murúa 2001: 103 [1615: Libro I, Capitulo 31]), "sentavanse los señores a beber al sol" (Albornoz 1967: 24 [1582]), bebía el inca y bebía el sol (Lizárraga 1916: 198-199 [1591: Cap. 80]), generalmente indicando que el Ushnu era "para que bebiese el sol" (Cobo 1956:193 [1653: Libro 13, Capitulo 18]), para "brindar con el sol" (Hernández Príncipe 2003:743 [1621]), y lo que se le ofrecía se entendía "como que el sol se lo hubiese bebido" (Garcilazo de la Vega 1991:372 [1609:lib.6, Cap. 21]), asimismo, no solo bebía el Sol sino "daban de beber a las huacas" (Villagomez 1919:163 [1649: Capitulo 45]), daban de "beber a los mallquis, guacas y aguelos primero" (Noboa 2003:335 [1657: fol. 10]), daban de beber a los ídolos y después todos empezaban a beber (Taylor 2000:83 [1609]), bebían "lo presentes empezando de los mas ancianos" (Taylor 2003:101. 102 [1608]), y no solo beber sino también “comer" (Noboa 2003:335 [1657: fol. 10]).

- Los Brindis, que eran por lo tanto la acción social mas preponderante en los Ushnu, denominados también como "el convite del beber" (Garcilazo de la Vega 1991:372 [1609: lib.6, Cap. 21]), pues en la interacción ritual "bebía el inca con el sol hacedor y trueno" (Molina 2008:160 [1575: fol. 14r.]), en este brindis, el Inka tenia dos vasos y "bebía el inca del vaso de la mano izquierda" (Garcilazo de la Vega 1991:372 [1609:lib.6, Cap. 21]), se brindaba con los ancestros, pues brindaban con los muertos (Pizarro 1968:495 [1571]), "bebían unos con otros los sacerdotes con los muertos" (Molina 2008:160 [1575: fol. 14r.]).

- La acción de hacer beber a los difuntos enterrados se realizaba a través de ductos hacia sus tumbas, pues se indica que daban de beber a estos por un "arcadus" (Hernández Príncipe 2003:745 [1621]).

- La acción de emborracharse por parte de las Huacas, pues en el caso de Huarochirí, la población que asistía a la fiesta decía "nuestro padre (Llocllahuancupa) ya esta borracho" (Taylor 2003:101-102 [1608]), pues la Huaca es "quien bebe" (Taylor 2003:101-102 [1608]).

- La acción de comer (Noboa 2003:335 [1657: fol. 10]), pues e dice que "servían la comida al sol" (Sarmiento de Gamboa 1943:187 [1572: Cap. 36]), o daban de comer al Sol (Betanzos 1987:52-53 [1551]).

- La acción de quemar (Las Casas 1892: 58 [1561]), quemar llamas refiriéndose como "corderos" (Betanzos 1987:51 [1551]).

- Entierros de ofrendas o "bulticos" (Betanzos 1987:53 [1551]), "dentro de la pila arrimados a las paredes della" (Betanzos 1987:53 [1551]), que probablemente eran pequeños ídolos.

- La acción de "mochar" (Villagomez 1919:163 [1649: Capitulo 45]; Noboa 2003:351 [1657: fol. 19v.]; Noboa 2003:429 [1657: fol. 63v.]; Noboa 2003:331 [1657: fol.6]), o entendiéndose como reverenciar "mochar" (Albornoz 1967: 19 [1582]).

- Realizar oraciones, pedir o rezar por buenas chacras de maíz y coca (Noboa 2003:429 [1657: fol. 63v.]).

- La acción de adornar "con paños de pluma y chaquira" (Cieza de León 1986:91 [1553: fol.38v.]), o embellecer (Taylor 2003: 92 93 [1608]) el lugar donde se encontraba el Ushnu.

\section{Acciones sociales y políticas}

El fundar un Ushnu al parecer era una actividad en la que se desarrollaban prácticas sociales que involucraba la participación de todas las familias reales de los Inkas, al menos eso se entiende 
cuando empezaron a construir el Ushnu de la plaza del Cuzco (Betanzos 1987:53 [1551]), y de este modo ciertos ritos de iniciación estaban vinculados también a los jóvenes de familias reales, pues se dice que al Ushnu se "ofrecían los que se hacían orejones" (Cobo 2003:202 [1653]).

Las actividades sociales públicas se realizaban en torno al Ushnu o al pie de este, y como lugar exclusivo de personajes importantes, estos lugares sobre elevados, eran desde donde se podía ver los bailes y fiestas (Cieza de León 1995:252 [1553: fol.115v.]), y las autoridades podían dirigirse a las poblaciones en sus discursos (Molina 1968: 316 [1553]).

Asimismo, de estos lugares la autoridad podía regular ciertas actividades o mantener orden (Cieza de León 1986:69 [1553: fol.30v.]), y por lo tanto se concebía a este lugar como un "Tribunal de juez" (Gonzales Holguín 1989:358 [1608]), o lugar que se debía respetar como un tribunal o mojón (Gonzales Holguín 1989:358 [1608]); y en la época Inka al parecer fue obligatorio construir los Ushnu para las diferentes actividades pero sobre todo para los principales rituales públicos al considerarse esta disposición como "ley y sacrificio de los incas" (Guaman Poma 1987:254 [1615: fol. 262[264]]).

\section{Acciones militares}

Al parecer, las acciones militares estaban también muy vinculadas a las funciones del Ushnu, así lo demuestran diferentes fuentes, al decir que desde esta estructura se llevaba el "orden de guerra" (Cieza de León 1986:69 [1553: fol.30v.]), se daba las órdenes y los "capitanes dan obediencia” (Santa Cruz Pachacuti 1995:92 [1613: fol. 32r.]), y la piedra que estaba en el Ushnu del Cuzco era conocida como la "piedra de la guerra" (Cieza de León 1986:69 [1553: fol.30v.]). Desde el Ushnu se podía "ver la gente de guerra cuando hacian sus reseñas y juntas" (Molina 1968: 316 [1553]), juntas "a punto de guerra" que podían congregar "400 indios alrededor de la dicha pila" (Molina 2008:155 [1575: fol. 11v.]), por lo que para esta actividad castrense era necesario hacer "usnus" por lo que el Inka "cuando quería hacer conquistas enviaba a sus capitanes y gente" a hacer "usnus" (Santa Cruz Pachacuti 1995:22 [1613: fol. 9v.]), "para ver si yban con buena orden de guerra y en cada guamanin de treinta leguas los visita que numero de gente lleua cada capitán" (Santa Cruz Pachacuti 1995:92 [1613: fol. 33v.]), y el Inka en estas actividades estaba "cercado de sus capitanes” (Guaman Poma 1987:392 [1615: fol. 385[387]]).

\section{Acciones tecnológicas y astronómicas realizadas en el Ushnu}

Si bien el Ushnu está asociado a las principales fiestas y actividades rituales que se daban durante el año, solo una fuente indica que esta estructura tenía una función astronómica, pues era un "pilar" que servía para "tomar el punto del sol" (Anónimo 1906:151 [Ca. 1565]) y de esta forma "cuando estaba ajustado entre los dos pilares era el tiempo de sembrar en los valles del Cuzco", por lo que se entiende que el Ushnu se empleaba para determinar fechas con cierta precisión, e iniciar actividades especificas.

\section{OBJETOS RITUALES ASOCIADOS AL USHNU}

\section{Sobre los bienes consumidos $u$ ofrendados en el Ushnu}

Los documentos revisados como ya se indico muestran que, el Ushnu fue un lugar eminentemente ceremonial, y servía para realizar libaciones, ofrendas y sacrificios, al respecto también estas mismas fuentes detallan todo lo que se ofrendaba, tal como:

- Chicha principalmente, así lo aseveran la mayoría de las fuentes, o bebida fermentada de maíz (Sancho de la Hoz 1968:331-332 [1534: Capitulo 18]; Betanzos 1987:185 [1551]; Betanzos 1987:52 [1551], Las Casas 1892: 132 [1561]; Anónimo 1906:158 [Ca. 1565]; Pizarro 1968:495 [1571]; Pizarro 1968:496 [1571]; Molina 2008:155 [1575: fol. 11v.]; Molina 2008:160 [1575: fol. 14r.]; 
Taylor 2003:101-102 [1608]; Taylor 2000:83 [1609]; Murúa 2001: 103 [1615: Libro I, Capitulo 31]; Hernández Príncipe 2003:743 [1621]; Villagomez 1919:157 [1649: Capitulo 44]; Villagomez 1919:163 [1649: Capitulo 45]; Noboa 2003:331 [1657: fol.6]; Noboa 2003:335 [1657: fol. 10]), en muchas cantidades (Lizárraga 1916: 198-199 [1591: Cap. 80]), algunos españoles denominaron a esta bebida ofrendada como "vino" (Ruiz de Arce 1968:432 [1545]), "vinos" que se daba en cantidad (Las Casas 1892: 58 [1561]), y que esta bebida que la hacían las mamaconas (Sarmiento de Gamboa 1943:187 [1572: Cap. 36]).

- "Brebajes", termino para referirse también a la chicha (Cieza de León 1995:277 [1553: fol.126v.]; Las Casas 1892: 132 [1561]; Sarmiento de Gamboa 1943:187 [1572: Cap. 36]).

- Maíz (Ruiz de Arce 1968:432 [1545]; Betanzos 1987:51 [1551]; Betanzos 1987:51 [1551]; Betanzos 1987:52 [1551]; Las Casas 1892: 132 [1561]), en muchos caso este era quemado.

- Coca (Betanzos 1987:51 [1551]; Noboa 2003:351 [1657: fol. 19v.]; Noboa 2003:429 [1657: fol. 63v.]; Noboa 2003:331 [1657: fol.6]).

- Animales (Cieza de León 1995:252 [1553: fol.115v.]), que frecuentemente eran camélidos denominados por los españoles como “ovejas y corderos" (Betanzos 1987:185 [1551]; Betanzos 1987:51 [1551]; Betanzos 1987:53 [1551]; Anónimo 1906:158 [Ca. $1565]$ ), en gran numero en cada fiesta como "mas de quinientas ovejas" (Betanzos 1987:53 [1551]), y que estos camélidos eran quemados por lo que se mandaba "hacer fuego para quemar corderos" (Betanzos 1987:51 [1551]; Betanzos 1987:51 [1551]; Betanzos 1987:52 [1551]); también eran sacrificados cuyes (Hernández Príncipe 2003:745 [1621]; Noboa 2003:351 [1657: fol. 19v.]), podía ser un "cuy blanco" (Noboa 2003:429 [1657: fol. 63v.]); aves como "pajaricos" (Betanzos 1987:52 [1551]).
- Cenizas (Pizarro 1968:496 [1571]).

- Ropa (Betanzos 1987:51 [1551]; Anónimo 1906:158 [Ca. 1565]) la cual también podía ser quemada.

- "Niños" (Betanzos 1987:51 [1551]), "niños tiernos" (Cieza de León 1995:252 [1553: fol.115v.]), sacrificio también denominado como "capacocha" (Guaman Poma 1987:254 [1615: fol. 262[264]]).

- Sangre (Cieza de León 1995:252 [1553: fol.115v.]), "sangre del cuye" (Noboa 2003:429 [1657: fol. 63v.]).

- Grasa o "sebo" (Noboa 2003:351 [1657: fol. 19v.]).

- Pestañas (Noboa 2003:429 [1657: fol. 63v.]).

- Idolillos, mencionados también como "bultos de oro" (Betanzos 1987:53 [1551]), "bulticos" (Betanzos 1987:53 [1551]) o "mojones de oro y plata" (Santa Cruz Pachacuti 1995:64 [1613: fol. 21r.]).

\section{Sobre los bienes utilitarios asociados en los rituales llevados a cabo en el Ushnu}

Los rituales que se realizaban en los Ushnu, sobre todo los de libación, implicaban la utilización de todo un conjunto de menajes. Las fuentes al respecto refieren las siguientes cosas:

- Recipientes o receptáculos, pues se indican que eran "cangilones" (Pizarro 1968:495 [1571]), "verquis" o virques (Pizarro 1968:495 [1571]). (ver Fig. 6)

- "Jarro" (Ruiz de Arce 1968:432 [1545]), posiblemente para referirse a un vaso.

- Vasijas, pues se menciona que se usaba "vasijas de donde vierten" la chicha (Cieza de León 1995:277 [1553: fol.126v.]; Ramos Gavilán 1988: 116 [1621:lib.1, cap. 17]), "vasijas de diferentes formas y materias" (Villagomez 1919:163 [1649: Capitulo 45]).

- Vasos, o Keros (Sarmiento de Gamboa 1943:187 [1572: Cap. 36]; Garcilazo de la Vega 1991:372 [1609:lib.6, Cap. 21]; Villagomez 1919:163 [1649: Capitulo 45]), "vasos de barro" (Sarmiento de Gamboa 


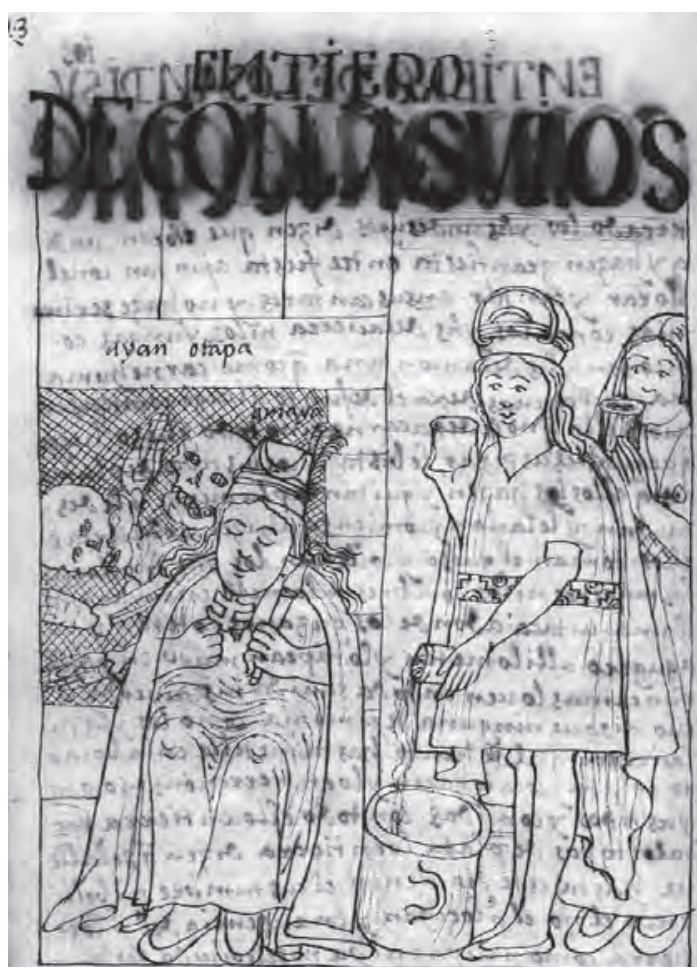

Figura 6: Momia de la zona del Collasuyo bebiendo en un gran recipiente (Guaman Poma 1987 [1615]).

1943:187 [1572: Cap. 36]), "vaso de oro grande" para referirse a una aquilla o vaso de metal con forma de kero (Molina 2008:160 [1575: fol. 14r.]), pues estas eran traídas por la "Coya acompañada de las pallas traia la chicha en dos aquillas de oro" (Hernández Príncipe 2003:743 [1621]), estos vasos algunas veces podían ser pequeños como un "quero minusculo" (Taylor 2003:101-102 [1608]).

- Olla al pie de una deidad, en algunos caso para colocar el kero con la bebida, para así dar a entender que estaba bebiendo las huacas (Taylor 2003:101-102 [1608]).

- mates o recipientes de la corteza de las cucurbitáceas (Taylor 2000:83 [1609]; Noboa 2003:335 [1657: fol. 10]); y se refiere en el caso de Huarochirí que era un "mate en el que el demonio llocllahuancupa había bebido" (Taylor 2003:101-102 [1608]).

- Brasero o recipiente para quemar ofrendas, se menciona como si fuera un "brasero"
(Ruiz de Arce 1968:432 [1545]) (Betanzos 1987:52 [1551]).

\section{Sobre los objetos con significado simbólico}

Sobre el Ushnu no solo se posicionaban los oficiantes y personajes importantes con ofrendas, sino también se colocaban los objetos de culto, que venían a ser las imágenes de las deidades, y son mencionadas como:

- Ídolos (Ruiz de Arce 1968:432 [1545]; Betanzos 1987:52 [1551]); Betanzos 1987:53 [1551]), "Idolo en piedra" (Betanzos 1987:53 [1551]), "piedra redonda que tenían por ídolo" (Pizarro 1968:495 [1571]), "estatua e idolo del sol” (Sarmiento de Gamboa 1943:187 [1572: Cap. 36]), "bulto del sol" (Betanzos 1987:51 [1551]), ídolo al que le ofrecían unos mates de chicha (Taylor 2000:83 [1609]), ídolos maniatados (Santa Cruz Pachacuti 1995:64 [1613: fol. 21r.]), ídolos en las plazas (Noboa 2003:331 [1657: fol.6]).

- Huacas (Villagomez 1919:163 [1649: Capitulo 45]), "sobre la que se derramaba la chicha" (Villagomez 1919:157 [1649: Capitulo 44]).

- "Cruz", como la que esta puesta sobre la piedra sagrada de la Isla del sol en el lago Titicaca (Ramos Gavilán 1988: 116 [1621: lib.1, cap. 17]).

\section{CONClusiones}

\section{Libación, Chicha y Ushnu en la época Inka}

Los rituales de libación en la época Inka, definitivamente fueron la actividad principal de las ceremonias públicas, en las que no solo participaban autoridades y poblaciones, sino de forma muy activa las deidades y los difuntos, y ofrecer chicha era el principal rito de culto a todo lo que consideraban sagrado. (ver Fig. 7).

El lugar que servía para los principales rituales públicos muy probablemente fue conocido por los españoles del siglo XVI y XVII como "Usno" tal como muestran las evidencias 


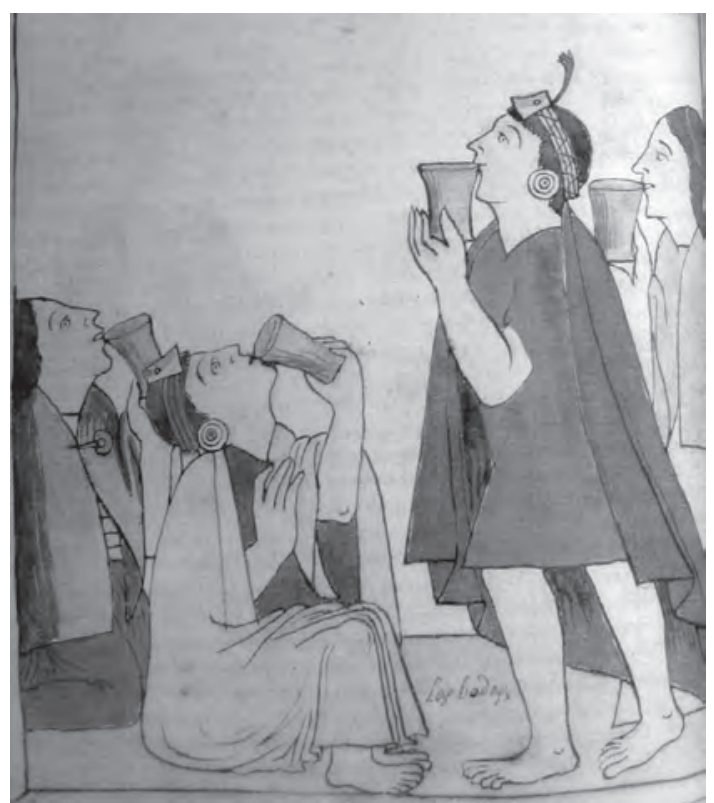

Figura 7: Personajes nobles de linaje Inka en actitud de libación (Murúa 2004[1590]).

históricas analizadas, y no como se le denomina actualmente con el término Ushnu palabra quechua que es usada en la actualidad en las zonas altas de Huánuco y Ancash (Pino 2005: 143-161) para referirse a lugar donde se filtran los líquidos, por lo que consecuentemente, se percibe una relación entre la acción de absorber o filtrar con beber. Y como se dijo, metodológicamente se continuara utilizando el término de Ushnu para evitar confusiones.

El Ushnu de la época Inka por lo tanto, era una construcción que se debía encontrar en cada poblado importante de cada provincia inka o wamani, los Ushnu que más se recuerda era los que se encontraban en Cuzco y Vilcashuaman, siendo éste el principal lugar para el Sapa Inka cuando estaba en público, ubicándose sobre éste sitio el Inka, que generalmente estaba acompañado de la imagen de las deidades especialmente del ídolo del Sol y de los Yllapas o cuerpos de los Inkas difuntos. Este lugar era principalmente usado en las fiestas, su posición central en las plazas y su diseño de plataforma sobre-elevada lo caracterizaba como un lugar protagónico en las reuniones sociales, al cual se accedía por unas gradas a lo alto de su cima, en la que se encontraba el lugar que servía de asiento del Sapa Inka. Además, la estructura estaba cubierta con oro, y poseía un receptáculo para la recepción de ofrendas liquidas, las cuales eran evacuadas por unos canales de drenaje que se dirigían a los recintos de las deidades. Las libaciones de chicha, en la cima del Ushnu, consistían en utilizar vasos para brindar con las deidades y los ancestros, para luego verter estas ofrendas liquidas en el receptáculo descrito para que se dé por aceptado socialmente que las deidades y ancestros habían bebido.

Asimismo, los Ushnu que fundaron los Inkas, tenían un carácter de complejidad por sus múltiples funciones, y esta complejidad podía ser evidenciada posiblemente en su diseño, que solo se puede corroborar mediante investigación arqueológica. Aproximaciones al carácter de complejidad y significado del Ushnu son referidos también en otros estudios desarrollados en las últimas décadas (Zuidema 1989: 402-454; Rowe 2003: 231; Matos 1986: 45-61; Hyslop 1990: 69-101; Meddens 1997; 5-14; Pino 2005: 143-161).

\section{Yllapa Usno o el culto a los ancestros más importantes}

Según la versión de Felipe Guaman Poma, y que por cierto es muy conocida, en su Nueva Cróni$\mathrm{ca}$, este autor indígena manifiesta que al cuerpo del difunto Inka le llamaron "Yllapa" por ser del Inka mismo, y esta mención es acompañada de un gráfico (Guaman Poma 1987:284-285 [1615: fol. 287-288[289-290]]), lo interesante de esta información es que el cronista indígena muestra en el gráfico adjunto, el ritual de libación en el que un Inka vivo da de beber al cuerpo del Inka difunto en un recipiente grande y la momia lleva etiquetado el nombre de "yllapa difunto". También en este documento, de la misma forma y casi con los mismos detalles, se observa el brindis cuando dan de beber a un importante personaje fallecido de los Collasuyos (Guaman Poma 1987:290-291 [1615: fol. 293-294[295-296]]). 
Según otra versión, se coincide en denominar a los cuerpos de los fallecidos mas importantes como Yllapa, tal como indica Cristóbal de Albornoz: "Hay otros géneros de guacas que se llaman yllapas, que son cuerpos muertos embalsamados de algunos pasados suyos principales, a los cuales reverencian y mochan" (Albornoz 1967: 19 [1582]), correspondiendo estos cuerpos a cada ayllu, parcialidad grupo familiar, donde el culto de estos Yllapa estaba a cargo de sus descendientes, por lo tanto era un culto a sus ancestros respectivos, que continuaban participando de las actividades sociales importantes como cuerpos embalsamados a quienes obligatoriamente se les daba de beber como en el caso de las momias Inka (Molina 2008:160 [1575: fol. 14r.]), momias que en las reuniones eran ubicadas al costado del Inka vivo y de las imágenes de las deidades, interactuando como una familia pero a nivel divino.

Sin embargo, cada uno de estos personajes, ya sean deidades o momias, debió tener sus propios recipientes para las libaciones, tal como se mostró al analizar los menajes que se utilizaba en los rituales de libación (Fig. 8). Luces sobre aspecto, nos la brinda la documentación de 1584 presentada líneas arriba correspondiente a Cristóbal de Albornoz, quien fue también un sacerdote extirpador de idolatrías en el siglo XVI (Duviols 1989), y que estuvo realizando esta labor eclesiástica en las áreas de Cuzco y Guamanga, que en 1584 reportó el descubrimiento y destrucción de muchas Huacas en el área de Soras cerca de Huamanga (Albornoz 1990: 255-296 [1584: fol. 42r.- 68v.]), y que las enlisto bajo el título de "Las guacas adoratorios e ydolatrias que se hallaron en este curazgo de los Soras" (Albornoz 1990: 264 [1584:

Figura 8: Recipiente de cerámica con forma de conjunto arquitectónico Inka elaborado para rituales de libación (Museo Inka del Cuzco). fol. 47v.]). Según se ha mostrado las referencias sobre el Yllapa y los Usno son abundantes, y que invitan a pensar que debió haber muchos receptáculos de rituales de libación denominados Yllapa Usno para cada personaje importante fallecido correspondiente a cada parcialidad o kuracazgo, pues estos Yllapa Usno se encontraban en poder de las autoridades o "caciques" de cada parcialidad o ayllu (Albornoz 1990: 264 [1584: fol. 47v.]). Por lo tanto, en el caso del culto a ancestros de grandes grupos familiares denominadas como parcialidades, estos ancestros conformados por los cuerpos embalsamados, debieron tener cada uno su propio Yllapa Usno para los brindis correspondientes y que por lo tanto hay una gran posibilidad que estos hayan sido de carácter mueble, para que de esta manera se hayan podido transportar donde haya tenido que ir el Yllapa para cumplir con sus compromisos sociales. De esta manera, se entiende que para los rituales de libación en las reuniones del Estado Inka, también el ídolo del Sol haya poseído su propio receptáculo como la mayoría de las fuentes lo menciona en este estudio, pero que en este caso había uno en la plaza y otro en los espacios interiores de su residencia, ambos con características más complejas por ser la imagen del Sol el ancestro común de los linajes Inka y partícipe protagónico de las reuniones públicas con carácter estatal.

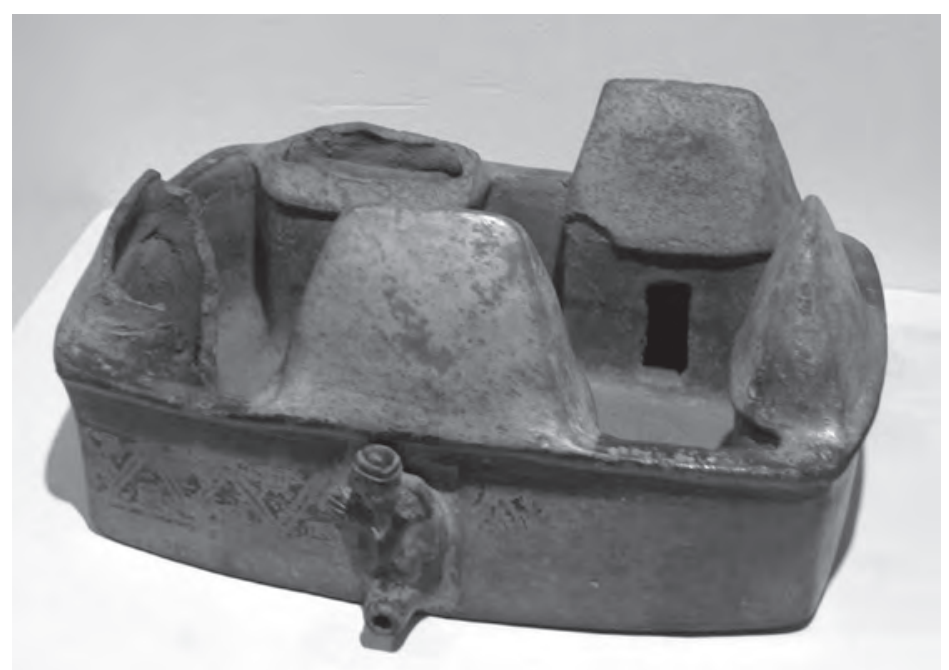




\section{Agradecimientos}

Mis cordiales agradecimientos a Ramiro Matos e Idilio Santillana por las asesorías y lecturas a mis textos. A Gabriel Ramón y Hernán Ramos por sus sugerencias, opiniones y críticas. A Tom Zuidema y Gary Urton por las conversaciones sobre el tema. A Marco Curatola debido a que una parte de este estudio fue desarrollado y asesorado en el seminario de Etnohistoria Colonial del Programa de Estudios Andinos. Y las gracias infinitas a Norma, mi madre por la paciencia de siempre y su asesoría en algunos términos quechua.

\section{BIBLIOGRAFÍA}

Agurto Calvo, Santiago

1987 Estudios acerca de la construcción, arquitectura y planeamiento incas. Cámara Peruana de la Construcción CAPECO. Lima.

Arriaga, Pablo José

1920 [1621] La extirpación de la Idolatría en el Perú. Colección de Libros y Documentos referentes a la Historia del Perú, Tomo I, 2da Serie. Imprenta y Librería Sanmarti y Ca.

Albornoz, Cristóbal

1967 [1582] "La Instrucción para descubrir todas las guacas del Pirú y sus camayos y haziendas". Editado por P. Duviols. Journal de la Société des Américanistes 56: 9-39.

1990 [1584] "Relación de la visita de extirpación de Idolatrías, anexos de la información de 1584". En El Retorno de las Huacas, estudios y documentos sobre el Taki Onqoy, siglo XVI. Luis Millones compilador. IEP, SPP. Lima.

Anónimo

1906 [1565] "Discurso de la sucesión y gobierno de los Yngas". Sección de Manuscritos Vol. J133, Num. 2.010, de la Biblioteca Nacional de Madrid. En Juicio de Limites entre El Perú y Bolivia. Tomo Octavo Chunchos. Victor M. Maurtua editor. Madrid.
Avendaño, Fernando de

2002 [1649] "Sermones de los misterios de nuestra santa fe católica en lengua castellana y la general del Inca". En Sermones y ejemplos. Antología bilingüe castellano-quechua. Siglo XVII. IFEA -Lluvia Editores, Lima.

Ávila, Francisco de

2002 [1646] "La Epifanía del señor y pascua de los Reyes". En Sermones y ejemplos. Antología bilingüe castellano-quechua. Siglo XVII. IFEA -Lluvia Editores, Lima.

Bertonio, Ludovico

2006 [1612] Vocabulario de la Lengva Aymara. Ediciones El Lector. Arequipa.

Betanzos, Juan de

1987 [1551] Suma y Narración de los Incas. Transcripción, notas y prologo por María del Carmen Martín Rubio. Atlas, Madrid.

Cieza de León, Pedro de

1995 [1553] Crónica del Perú. Primera Parte. Fondo Editorial de la PUCP, Academia Nacional de Historia. Lima.

1986 [1553] Crónica del Perú. Segunda Parte. Fondo Editorial de la PUCP, Academia Nacional de Historia. Lima.

Cobo, Bernabé

1956 [1653] Historia del Nuevo Mundo. BAE, Tomo nonagésimo segundo. Obras del Padre Bernabé Cobo de la Compañía de Jesús II. Madrid.

1979 [1653] "Relación de las guacas del Cuzco". En "An account of the shrines of ancient Cuzco". Estudio Introductorio de John H. Rowe. Nawpa Pacha 17: 2-80.

2003 [1653] "Relación de las guacas del Cuzco. Una relación de los adoratorios del antiguo Cuzco". En Los Incas del Cuzco, Siglos XVI - XVII - XVII. Compilación de estudios de John Howland Rowe. Pp. 181-230. INC - Región Cusco.

Duviols, Pierre

2003 Procesos y visitas de idolatrías. Cajatambo, siglo XVII, con documentos anexos. IFEA, PUCP. Lima. 
1989 Introducción y notas a la "La Instrucción para descubrir todas las guacas del Pirú y sus camayos y haziendas". En Fábulas y mitos de los incas. Edición de Henrique Urbano y Pierre Duviols. Historia 16, Crónicas de América 48, Madrid.

Garcilaso de la Vega, Inca

1991 [1609] Comentarios Reales de los Incas. Tomo I y II. Edición de Carlos Aranibar. Fondo de Cultura Económica. Lima.

Gili Gaya, Samuel Ed.

1953 Vox, Diccionario General Ilustrado de la Lengua Española. Editorial Spes S.A., Barcelona.

Gonzales Holguín, Diego

1989 [1608] Vocabvlario de la Lengva general de todo el Perv llamada Lengua Qquichua o del Inca. UNMSM. Lima.

Guamán Poma de Ayala, Felipe

1987 [1615] El Primer Nueva Corónica y Buen Gobierno. Editado por John Murra, Rolena Adorno y Jorge L. Urioste. Historia 16, Crónicas de América 29a-c, Madrid.

Hernández Príncipe, Rodrigo

2003 [1621] "Idolatría del pueblo de Ocros cabeza desta comunidad. Año de 1621. Visita de Rodrigo Hernández Príncipe a Ocros (1621)". En Procesos y Visitas de Idolatrías, Cajatambo, Siglo XVII. Edición de Pierre Duviols. Fondo Editorial de la PUCP, Instituto Francés de Estudios Andinos. Lima.

Las Casas, Bartolomé de

1892 [1561] De las antiguas gentes del Perú. Librería de Murillo, Alcalá.

Lizárraga, Reginaldo de

1916 [1591] Descripción Colonial. Libro Primero. Biblioteca Argentina, Director Ricardo Rojas. Buenos Aires.

Matos, Ramiro

1986 "El Ushnu de Pumpu”. Cuicuilco 18: 45-61. Mexico.

Meddens, Frank

1997 "Function and meaning of the usnu in Late Horizon Peru". Tawantinsuyu 3:
$5-14$.

Molina, Cristóbal de (el Cuzqueño)

1989 [1575] "Relación de las Fábulas y Ritos de los Incas". En Fábulas y mitos de los incas. Edición de Enrique urbano y Pierre Duviols. Historia 16, Crónicas de América 48, Madrid.

2008 [1575] Relación de las Fábulas y Ritos de los Incas. Edición, estudios y notas por Julio Calvo Pérez y Henrique Urbano. Fondo Editorial de la USMP, Lima.

Molina, Cristóbal de (el Chileno)

1968 [1553] "Conquista y población del Perú o destrucción del Perú”. En Biblioteca Peruana. El Perú a través de los siglos. Primera Serie. Tomo III. Facultad de Letras y Ciencias Humanas de la UNMSM. Editores Técnicos Asociados S.A. Lima.

Murúa, Fray Martín de

2001 [1615] Historia General del Perú. Edición de Manuel Ballesteros Gaibrois. Crónicas de Ámerica, Dastin, S.L. Madrid.

2004 [1590] "Historia del Origen y Genealogía Real de los Reyes Ingas del Piru de sus Hechos, Costumbres, Trajes, y Manera de Gobierno". En Códice Murúa. Manuscrito Galvín. Estudio de Juan Ossio. Testimonio Compañía Editorial, S.A. y SEACEX Asociación Cultural Exterior. Madrid.

Noboa Sotela, Bernardo de

2003 [1657] "Denuncia que hace don Juan Tocas principal y fiscal de la dicha visita contra Hernando Hacas Cristobal Poma Libiac y muchos indios del pueblo de San Pedro de Hacas. Legajo III, expediente 11. Visitas y Procesos". En Procesos y Visitas de Idolatrías, Cajatambo, Siglo XVII. Edición de Pierre Duviols. Fondo Editorial de la PUCP, Instituto Francés de Estudios Andinos. Lima.

Pino Matos, José Luis

2005 "El Ushnu y la organización espacial astronómica en la sierra central del Chinchaysuyu". En Estudios Atacameños № 29, Páginas 143-161. Universi- 
dad Católica del Norte, San Pedro de Atacama, Chile.

Pizarro, Pedro

1968 [1571] "Relación del Descubrimiento y Conquista de los reinos del Perú". En Biblioteca Peruana. El Perú a través de los siglos. Primera Serie. Tomo I. Facultad de Letras y Ciencias Humanas de la UNMSM. Editores Técnicos Asociados S.A. Lima.

Ramos Gavilán, Alonso

1988 [1621] Historia del Santuario de Nuestra Señora de Copacabana. Editado por Ignacio Prado Pastor. Talleres Gráficos Villanueva. Lima

Rowe, John

2003 "Hawkaypata: Como fue la plaza de los Inkas". En Los Incas del Cuzco, Siglos XVI-XVIII, pags. 231-235. INC Cuzco.

Ruiz de Arce, Juan de

1968 [1545] "Advertencias". En Biblioteca Peruana. El Perú a través de los siglos. Primera Serie. Tomo I. Facultad de Letras y Ciencias Humanas de la UNMSM. Editores Técnicos Asociados S.A. Lima.

Salomon, Frank

2006 Los Quipocamayos. El antiguo arte del khipu en una comunidad campesina moderna. IFEA-IEP. Lima.

Sancho de la Hoz, Pedro

1968 [1534] "Relación para su Majestad". En Biblioteca Peruana. El Perú a través de los siglos. Primera Serie. Tomo I. Facultad de Letras y Ciencias Humanas de la UNMSM. Editores Técnicos Asociados S.A. Lima.

Santa Cruz Pachacuti Yamqui Salcamayhua, Joan de

1995 [1613] Relación de antigüedades de este reino del Perú. Edición, índice analítico y glosario de Carlos Aranibar. Fondo de Cultura Económica, Lima.

Santo Thomas, Fray Domingo de

2006 [1560] Léxico Quechua. Edición y comentarios de Jan Szemiñski. Convento de Santo Domingo - Qorikancha, The He- brew University of Jerusalem, Sociedad Polaca de Estudios Latinoamericanos. Ediciones El Santo Oficio. Lima.

Sarmiento de Gamboa, Pedro

1943 [1572] Historia de los Incas. Emecé Editores, S.A. Buenos Aires.

Taylor, Gerald

1999 [1608] Ritos y Tradiciones de Huarochirí. Instituto Francés de Estudios Andinos, Banco Central de Reserva del Perú y Universidad Ricardo Palma. Lima.

2000 [1609] "Carta Annua de 1609. Extractos". En Camac, camay y camasca, y otros ensayos sobre Huarochirí y Yauyos. Instituto Francés de Estudios Andinos, Lima.

2003 [1608] Ritos y Tradiciones de Huarochirí, Manuscrito Quechua del siglo XVII. IFEA, Lluvia Editores.

Titu Cusi Yupanqui, Inga Diego de Castro

1992 [1570] Instrucción al Licenciado Don Lope García de Castro. Estudio preliminar y edición de Liliana Regalado. Fondo Editorial de la PUCP. Lima.

Valera, Blas

1945 [1585] La Costumbres Antiguas del Perú y La Historia de los Incas (Siglo XVI). Introducción, adiciones, notas y comentarios de Francisco A. Loayza. Los Pequeños Grandes Libros de Historia Americana, Serie I, Tomo VIII. Lima.

Vega- Centeno Sara-Lafosse, Rafael

2006 "El estudio arqueológico del ritual". En Investigaciones Sociales Año X $\mathrm{N}^{\circ}$ 16, pp. 171-192. UNMSM.

Villagomez, Pedro de

1919 [1649] Exhortaciones e Instrucción acerca de las Idolatrías de los Indios del arzobispado de Lima. CLDRHP, Tomo 12. Imprenta y Librería Sanmartí y Ca. Lima.

Zuidema, Tom

1989 "El Ushnu". En Reyes y Guerreros, ensayos de cultura andina. Manuel Burga Compilador. FOMCIENCIAS. Lima. 